NASA Technical Memorandum 83276

\title{
MEASURED AND CALCULATED. EFFECTS OF ANGLE OF ATTACK ON THE TRANSONIC FLUTTER OF A. SUPERCRITICAL WING
}

E. CARSON YATES, JR., ELEANOR. C, WYNNE, AND MOSES G. FAPMER

AUGUST 1982

\author{
URARY SOPY \\ 16161982
LANGLEY RESEARCH CENTER
LIBRARY, NASA
HAMPTON, VIRGINIA

\section{nusn \\ National Aeronautics and Space Administration



MEASURED AND CALCULATED EFFECTS OF ANGLE OF ATTACK

ON THE TRANSONIC FLUTTER OF A SUPERCRITICAL. WING

\author{
E. Carson Yates, Jr. , Eleanor C. Wynne, and Moses G. Farmer \\ NASA Langley Research Center \\ Hampton, Virginia 23665
}

\section{Abstract}

Flutter calculations have been made by modified strip analysis employing steady-state aerodynamic parameters obtained from published wind-tunnel pressure distributions. The results indicate that increasing angle of attack from zero can produce substantial changes in the cransonic flutter characteristics that are favorable or unfavorable depending on Mach number and angle of attack. These results correlate well, in a qualitative sense, with the known aerodynamic behavior. The bottom of the transonic flutter-boundary "bucket" is shown to occur at lower Mach number as angle of attack increases.

The calculated flutter characteristics are in good agreement with the experimental data at zero angle of attack. At nonzero angles of attack, however, the experiments show sharply declining and backward-turning transonic flutter boundaries that are not indicated by the calculations. Published information indicates that such unconventional flutter boundaries may be caused by viscous effects at low Reynolds number which were not represented in the calculations. The present investigation indicates, however, that the occurrence of these unconventional transonic boundaries appears to be caused, at least to some extent, by variations in static aeroelastic deformation. A mechanism for the phenomenon is postulated.

\begin{tabular}{|c|c|}
\hline & Nomencl ature \\
\hline$a_{c, n}$ & $\begin{array}{l}\text { nondimensional distance from } \\
\text { midchord to section aerodynamic } \\
\text { center measured perpendicular to } \\
\text { elastic axis, positive rearward, } \\
\text { fraction of semichord }\end{array}$ \\
\hline$b_{r}$ & $\begin{array}{l}\text { semichord of wing measured } \\
\text { perpendicular to elastic axis at } \\
\text { spanwise reference station } n=0.75 \\
\left(b_{r}=0.14948 \mathrm{~m}\right)\end{array}$ \\
\hline $\mathrm{C}_{\ell}$ & $\begin{array}{l}\text { section lift coefficient for a } \\
\text { section perpendicular to elastic axis }\end{array}$ \\
\hline $\mathcal{C}_{\ell_{\alpha},}$ & $\begin{array}{l}\text { section lift-curve slope for a } \\
\text { section perpendicular to elastic axis }\end{array}$ \\
\hline$c_{m}$ & $\begin{array}{l}\text { section-pitching moment coefficient } \\
\text { referred to midchord for a section } \\
\text { perpendicular to elastic axis }\end{array}$ \\
\hline$H$ & $\begin{array}{l}\text { translational displacement of wing at } \\
\text { elastic axis, positive downward, } \\
\text { fraction of reference semichord } b_{r} \\
\text { freestream Mach number }\end{array}$ \\
\hline
\end{tabular}

\section{Nomencl ature} center measured perpendi elastic axis, positive rearward, ch semichord perpendicular to elastic axis at spanwise reference station $n=0.75$ $=0.14948 \mathrm{~m}$ section perpendicular to elastic axis section lift-curve slope for a section-pitching moment coefficient fraction of reference semichord $b_{r}$ $m_{r} \quad$ mass of wing per unit span at spanwise reference station $(\eta=0.75)$ $\left(m_{r}=2.57 \mathrm{~kg} / \mathrm{m}\right)$

q freestream dynamic pressure

$v \quad$ freestream speed

$v_{I} \quad$ flutter-speed index, $\frac{V}{\mathrm{~b}_{r} w_{r} \sqrt{\mu_{r}}}$

$\alpha \quad$ angle of attack at wing root

$n \quad$ nondimensional coordinate measured from wing root along elastic axis, fraction of elastic axis length

$\theta \quad$ torsional displacement of wing about elastic axis, positive leading edge up

ur mass ratio based on spanwise reference station $(n=0.75)$, $m_{r} / \pi \rho b_{r}^{2}$

$\rho \quad$ freestream density

$\omega$ circular frequency of vibration

$\omega_{r} \quad$ reference frequency, frequency of first uncoupled torsional mode of wing $\left(\omega_{r}=227.23 \mathrm{rad} / \mathrm{sec}\right)$

Subscripts:

$1,2,3$ notation used to distinguish the multiple flutter characteristics in Figs. $7(\mathrm{e})-(\mathrm{h})$

\section{Introduction}

It is well known that the use of super critical airfoils, instead of conventional airfoils, can have adverse effects on the transonic flutter characteristics of lifting surfaces. These effects include reduction of transonic flutter speeds $1-3$ and increased rate of degradation of flutter speed with small increases in angle of attack (e.g., Ref. 4). Since adequate theories for three-dimensional unsteady transonic flow have not yet been developed and verified, the modified strip analysis first published in $1958^{5-11}$ was used in reference 3 to predict (with good accuracy) the subsonic and transonic flutter characteristics for the wing of reference 1 at angles of attack near zero. The investigation reported here is an extension of the study of this wing to examine the effects of angle of attack between $0^{\circ}$ and $4^{\circ}$. Some previously unpublished experimental flutter data for this wing at angles of attack from $0^{0}$ to $3^{\circ}$ are also included and compared with calculated results.

The calculated results shown here have been made by the modified strip analysis which has given good flutter results for a broad range of swept and unswept wings at speeds up to hypersonic ${ }^{6}$, including effects of wing thickness 8,9 and angle of attack. 10 in particular, this method was used successfully to 
calculate transonic flutter characteristics for some swept wings with conventional airfoils, 7 as well as for the present swept supercritical wing.

\section{Flutter Model Parameters}

The wind-tunnel model used in the present study is that of reference 1 and is fully described in that report. Measured geometric, elastic, and inertial properties of this model were used in the calculations. The model geometry is shown in Fig. Ta. The frequencies and node lines of the first six measured natural vibration modes are presented in Fig. $1 \mathrm{~b}$, and the modal deflections are given in Fig. 2. The corresponding generalized masses were determined by the method of displaced frequencies. 12

These six measured modes were used in all of the flutter calculations. Some collateral calculations made in connection with the study of reference 3 indicated that six measured modes were sufficient to converge the flutter results within about one percent.

\section{Flutter Experiments}

The flutter tests were conducted in the Langley Transonic Dynamics Tunnel which has a slotted 4.88-meter (16-foot) square test section with cropped corners. Air was used as test medium, whereas Freon $-12^{\star}$ was used in the study of reference 1. Consequently, the mass ratios $\mu_{\mathrm{r}}$ for the present tests are considerably higher than those of reference 1 (see also ref. 3). Flutter data were obtained for wing-root angles of attack of $0^{0}, 1^{\circ}, 2^{0}$, and $3^{\circ}$.

\section{Flutter Analysis}

Method

The modified strip analysis 5 is formulated for wing strips oriented normal to the elastic axis and is based on stripwise application of Theodorsen-type aerodynamics 13 in which the lift-curve slope of $2 \pi$ and aerodynamic center at quarter chord are replaced, respectively, by the lift-curve slope and aerodynamic center for the same strip of the three-dimensional wing at the appropriate Mach number and angle of attack. The downwash collocation point, where the downwash induced by the aerodynamic load is set equal to the kinematic downwash, is modified accordingly. The circulation function is modified for compressibility by use of two-dimensional unsteady compressibleflow theory.14 Further description and discussion of this method are contained in references 5 to 7 and 11 .

\section{Aerodynamic Parameters}

The required spanwise distributions of section lift-curve slope and aerodynamic center

*Freon is a registered trademark of E.I. DuPont de Nemours Co., Inc. were obtained from steady-state surface pressure measurements made by Harris 15 in the Langley 8-Foot Transonic Pressure Tunnel. These pressures were integrated numerically as described in reference 3 to obtain section lift and pitching-moment coefficients at 40 stations along the semispan. At each station these section coefficients were numerically spline fitted as a function of angle of attack to obtain a continuous variation with angle of attack. Typical results at two stations $(n=0.5125$ and $n=0.7625$ ) are shown in Fig. 3 for $M=0.95$ and $q=28.7 \mathrm{kPa}(600 \mathrm{psf})$, in Fig. 4 for $M=0.99$ and $q=28.7 \mathrm{kPa}$ (600 psf), and in Fig. 5 for $M=0.99$ and $q=44.2 \mathrm{kPa}(923 \mathrm{psf})$.

The spline curves were differentiated analytically to obtain section lift-curve and moment-curve slopes and hence also section aerodynamic center for any desired angle of attack. Typical spanwise distributions of the resulting section lift-curve slope and aerodynamic center, which are input to the flutter calculations, are shown in Fig. 6 for two levels of dynamic pressure at each Mach number. The abrupt change in the spanwise slope of each curve inboard is caused by use of the dashed planform in Fig. 1 as reference while preserving the section lift and moment values for the wing with glove. As expected, Fig. 6 shows that changes in the aerodynamic parameters caused by changes in angle of attack become greater as Mach number increases.

In comparison with the present procedure, the experimental and calculated result of reference 3 were all for angle of attack below about $0.3^{\circ}$. Consequently, the $1 \mathrm{ift}$ and moment slopes used therein were obtained by fitting straight lines to the section aerodynamic coefficients for the angle of attack nearest zero and the next lowest positive angle of attack.

Since steady-state pressure data are avail. able from reference 15 for two levels of dynamic pressure at each Mach number, it is possible to assess the effect on aerodynamic parameters (and hence on flutter) of static aeroelastic deformation of the pressure model, together with an accompanying change in Reynolds number.* Consequently, the aerodynamic parameters for both levels of dynamic pressure (Fig. 6) are used in the flutter calculations.

\section{Mass Ratio}

Many of the flutter calculations presented here were made with mass ratio $\mu r=27.41$ in order to maintain continuity with Fig. 11 of reference 3. Other calculations have been made with higher mass ratios, especially for comparison with the present experimental data.

*Reynolds numbers of $2.0 \times 10^{6}$ and $3.0 \times 10^{6}$ (based on mean geometric chord) for $M>0.95$ are representative for the 8-foot tunnel tests. However, reference 3 indicated the effect of Reynolds number difference at each Mach number to be quite small, at least at the small angles of attack considered in that paper. 
Results and Discussion

Flutter calculations for Mass Ratio $\mu_{r}=27.41$

Figure 7 shows the effect of angle of attack on flutter-speed index, which is proportional to the square root of dynamic pressure, and flutter-frequency ratio for each of eight Mach numbers from 0.25 to 1.00 . In comparing the various parts of Fig. 7, note that the ordinate scale in parts (a) to (f) is stretched by a factor of $21 / 2$ relative to that used in parts $(\mathrm{g})$ and $(\mathrm{h})$. Aerodynamic parameters for both levels of dynamic pressure have been used at each Mach number as indicated by the solid and dash curves. The differences butween these curves indicate essentially the sifect of different static aeroelastic deformations of the aerodynamic model at the two levels of dynamic pressure.* Comparison of the solid and dash curves in each part of Fig. 7 confirms a result of reference 3 that using aerodynamic parameters for the two levels of dynamic pressure caused only minor differences in the calculated flutter speed for angles of attack near zero. Indeed, the differences shown here are less than two percent except at $M=0.99$ where the difference is about four percent. Moreover, the differences remain small up to four degrees angle of attack for Mach numbers up to 0.80 and up to three degress for $M=0.90$. Thus, as expected, aerodynamic hanges caused by static aeroelastic deformation of the aerodynamic model have little effect on flutter speeds in the subsonic range, even up to a few degrees angle of attack.

This result, which is consistent with the concepts of linearized aerodynamic theory, is not, however, caused by invariance of the associated aerodynamic parameters with changes in angle of attack as is evident in all parts of Fig. 6. At the lower Mach numbers, however, the changes that occur tend to have opposing influences on flutter speed. For example, Figs. 6 (a) and (b) show that even for $M=0.25$, increasing angle of attack decreases section lift-curve slope over the middle and outer portions of the wing. This change alone would be expected to increase the flutter speed. However, the accompanying forward movement of the aerodynamic centers tends to decrease flutter speed. The combined effect is virtually nil as is evident in Fig. 7(a).

Fig. 7 also shows that at each Mach number the effect of increasing angle of attack from zero is insignficant for the first few tenths of a degree. In the lower subsonic range the effect is minor all the way up to four degrees, which is again consistent with aerodynamic linearization. Even at $M=0.80$ (Fig. $7(\mathrm{c})$ ), the effect is slight until angle of attack reaches about three degrees, where a degradation of flutter speed appears to begin. At $M=0.90$ (Fig. $7(d)$ ), the degradation begins at about one degree. For Mach number 0.95 and above (Figs. $7(\mathrm{e})$ to $(\mathrm{h})$ ), the flutter characteristics are complicated by the appearance of mode changes, accompanied by abrupt changes in flutter

* See footnote on previous page. frequency (arrows), closed regions of flutter, and increased sensitivity to both variations in angle of attack and dynamic pressure level.* At $M=1.00$, however, the mode changes no longer occur. For these higher Mach numbers, the curves for the different flutter modes have been numbered as an aid in distinguishing them.

Although the trends may not be particularly significant, there is at least consistency in the meandering of the two flutter-frequency curves for each Mach number up to 0.95 (Figs. $7(a)$ to (e)). At the lowest angles of attack, the nigher flutter frequencies are generated by use of the higher $-q$ aerodynamic parameters. In the mid range of $\alpha$, the lower-q aerodynamic parameters produce the higher flutter frequencies. At higher angles of attack, the curves recross, and for the two higher Mach numbers, recross again. This pattern is broken at Mach number 0.98 and above (Figs. $7(f)$ and $(h))$, where the complicated mode changes appear.

The degradation of the flutter speed with increasing angle of attack (Fig. 7) is generally familiar, but the ensuing rise for Mach numbers 0.95 to 1.00 may not be, although it was anticipated from the variation of the aerodynamic parameters. To facilitate the discussion of this behavior, the flutter-speed curves for the lower dynamic pressure in Figs. $7(c)$ to $7(f)$ have been superimposed in Fig. 8. For $M=0.80$, the flow over the wing at small angles of attack is subsonic, and the associated variations of $C_{\ell_{\alpha, n}}$ and $a_{c}, n$ are much like those described previously for $M=0.25$. As angle of attack approaches three degrees, however, an embedded supersonic-flow region appears forward on the wing upper surface, causing the lifting pressure to increase rapidly there and the aerodynamic centers to move more rapidly forward (Fig. 6(e)). The effect on flutter speed at three degrees and beyond is detrimental. For $M=0.90$, the picture is qualitatively similar, but at this higher Mach number transonic effects start to become significant at about one degree angle of attack. Fig. $6(g)$ shows the related forward movement of aerodynamic center, as well as a rapid increase in $\mathrm{C}_{\ell_{\alpha, n}}$ which occurs at four degrees. The latter, however, occurs on portions of the span where the forward movement of the aerodynamic centers is relatively not so great. At this higher angle of attack, the supersonic-flow region is extensive and is growing primarily aftward (shock moving aft).

At $M=0.95$, qualitatively similar behavior starts almost at zero angle of attack. The effects of forward-moving aerodynamic center and increasing lift-curve slope over the outer portions of the wing are offset to some extent by opposite trends over the midsemispan (Fig. $6(i))$. The outer portions dominate, however, because they are weighted more heavily in the flutter motion, and the flutter speed, shown in

*Because of the complexity of the flutter characteristics shown, the flutter boundaries (lowest flutter speeds) that involve mode changes (Figs. $7(\mathrm{e})$ to $(\mathrm{g})$ ) are identified by a bold line. 
Figs. 7(e) and 8, declines with increasing angle of attack as at the lower Mach numbers. As angle of attack increases beyond three degrees, the aftward growth of the supersonic region causes the aerodynamic centers to move aftward again, and the flutter speed increases with increasing angle of attack.

At $M=0.98$, the supersonic region is ex tensive even at angles of attack near zero, and its aftward growth with increasing angle causes lift-curve slopes to increase and aerodynamic centers to move aft starting from $\alpha=0$ (Fig. $6(k))$. These are opposing effects on flutter speed. However, the latter dominates and causes flutter speed to rise monotonically as angle of at:ack increases from zero.

Fig. 9 shows crossplots of the flutter speeds from Fig. 7 for integer values of angle of attack. As expected, the Mach number at which the bottom of the "transonic bucket" occurs decreases as angle of attack increases. This result was expected because the onset and development of transonic-flow phenomena occur at lower Mach numbers as angle of attack increases. Similar behavior is shown in reference 16 for the flutter of two-dimensional airfoils calculated by use of the HYTRAN2 finitedifference code. In Fig. 9, the level of flutter speed at the bottom of the bucket varies relatively little with angle of attack except - hat it is appreciably higher at two degrees than at higher or lower angles. Moreover, for Mach numbers above 0.98 , a second dip occurs which for $\alpha=2^{0}$ drops considerably below the primary bucket. Second dips of this sort have been observed in wind-tunnel flutter tests 17 and have been speculatively related to disturbances reflected from tunnel walls. In this region of rapid change, aerodynamic data for the present calculations are not available at enough Mach numbers to define the shape of this second dip with precision. For example, at any particular angle of attack, the intersection of the primary bucket and the secondary dip is undoubtedly not exactly at the point shown in the figure.

It is possible that shock motion may contribute to the slightly early appearance of the calculated transonic bucket in reference 3 and may affect the accuracy of the present result. Use of the aerodynamic parameters obtained from measured steady-state pressure distributions in flutter calculations by the modified strip analysis implies that both shock displacements and viscous effects are incorporated in the same manner as other aerodynamic influences. Moreover, these effects are not represented on a purely quasi-steady basis but are implicitly combined with other aerodynamic effects and subjected to the same attenuations and phase shifts. However, it is well known (e.g., Ref. 18) that the variation with frequency of shock motion and associated phase lag may differ appreciably from the corresponding attenuations and lags for unisteady shock-free flow. The influence of these differences in the present calculations has not been assessed.

\section{Experimental Flutter Data}

Experimental flutter data for angles of attack from zero to three degrees are presented in Fig. 10, along with calculated flutter characteristics to be discussed subsequently. The solid symbols indicate "hard flutter" (divergent oscillation) points obtained during the tests; the open symbols indicate points of incipient flutter. The circles define the flutter boundary encountered with Mach number and dynamic pressure increasing, whereas the squares indicate flutter points obtained with Mach number and dynamic pressure decreasing. The associated value of mass ratio is indicated beside each "hard flutter" point. Although relatively few flutter points were obtained, they are sufficient to show the shapes of the flutter boundaries. Fig. 10(a), for example, shows the occurrence of a conventional "transonic bucket" for $\alpha=0^{\circ}$. These data are, in effect, the counterpart in air of the data given in reference 1 which were obtained with Freon as the test medium.

For nonzero angles of attack, on the other hand, Figs. 10(b), (c), and (d) show flutter boundaries that curve sharply downward and back ward toward lower Mach numbers with the sharpest drop (actually, vertical slope) occurring at progressively lower Mach number as angle of attack increases. These unconventional transonic buckets are qualitatively similar to those shown in reference 4 at angles of attack near zero for a supercritical wing with much less sweep than the present wing. The backward turn of the boundaries in reference 4 occurred after a very large decline in the boundary which was attributed to viscous effects at low Reynolds number. Specifically, some evidence indicated that boundary-layer transition strips designed for Reynolds numbers around $2 \times 10^{6}$ did not produce full transition at Reynolds numbers below $1 \times 10^{6}$. The result was an apparent increase in lift-curve slope and decrease in flutter speed at the lower Reynolds numbers. Similar influences may affect the result shown in Fig. 10. For the present tests in air, the transition-strip grit size and density were selected for a nominal Reynolds number of $1 \times 10^{6}$ based on mean geometric chord. However, at $\alpha=1^{0}$, Reynolds number is as low as $0.65 \times 10^{6}$ for the "hard" flutter point at the lowest value of flutter-speed index (lowest q) and at $\alpha=2^{\circ}$, it is as low as $0.42 x$ $10^{6}$. The consequences of these low Reynolds numbers have not been explicitly examined in this study. The backward turn in the present boundaries, however, appears to be associated also with variations in the static deformation of the model, as will be discussed below.

The experimental investigation of reference 4 did not produce any flutter points on the high-Mach-number side of the transonic bucket. A few such points were obtained during the present tests, however, and they provide some indication of the width of the unconventional bucket which occurs at nonzero angle of attack (Figs. 10(b), (c), and (d)). 
Comparison of Experiments and Calculations

For comparison with the experimental data, flutter calculations were made using the highest and lowest mass-ratio values for the hard flutter points at each angle of attack. The resulting curves in Fig. 10 show, as did Fig. 7, that using aerodynamic parameters obtained at two levels of dynamic pressure caused only minor differences in flutter speed for all Mach numbers at $\alpha=0^{0}$. (Fig. 10(a)) and for all angles of attack at Mach numbers 0.90 and below.

In Fig. 8 of reference 3 , the calculated flutter boundary for angle of attack near zero was about three percent conservative (below experiment) in the subsonic range. At much higher mass ratios, in Fig. 10(a), the calculated boundary is about six percent conservative relative to the one experimental flutter point near $M=0.85$. The corresponding flutter frequency is accurately predicted. In Fig. 8 of reference 3 , the depth of the transonic bucket was accurately calculated, but the onset of the calculated dip was at about 0.04 Mach number lower than the experimentally indicated onset. In Fig. 10(a), the onset appears to be accurately calculated, but the calculated bucket is a bit deeper than that obtained from the tests. As in Fig. 9 of reference 3 , the calculated flutter frequencies in the transonic range are a bit high. Comments in reference 3 concerning possible tunnel-wall effects and the ratio of model size to tunnel size for the aerodynamic tests ( 8 -foot Transonic Pressure Tunnel) and the flutter tests (Transonic Dynamics Tunnel) are relevant here also.

For $\alpha=10$ (Fig. 10(b)), the bottom of the unconventional experimental transonic bucket must be slightly above the incipient flutter point at about $M=0.985$ (open symbol). Even though the calculations produced a conventionally shaped bucket, the Mach number and flutter-speed level at the bottom of the bucket are predicted satisfactorily by the curve for $\mu_{r}=555$.

For $\alpha=2^{0}$ (Fig. $10(c)$ ), the calculated secondary transonic dip provides a reasonable approximation of the upper portion of the unconventional experimental bucket, especially the dash curve for the higher dynamic-pressure level. This observation is probably not significant, however, since there is no such correlation at $\alpha=3^{\circ}$, and the calculated flutter frequencies are high for both angles.

Finally, Fig. 11 presents an expanded-scale cross plot of data from Fig. 10 as a function of angle of attack. Mach numbers near 0.95 were chosen because that is the only narrowly limited range for which aerodynamic parameters were available for flutter calculations and experimental flutter points were available at all four angles. Agreement between calculations and experiments is good, except at $\alpha=2^{0}$ where the calculated value is somewhat high.
A Mechanism for the Unconventional Transonic Bucket

The multiple flutter modes and closed flutter regions in Figs. $7(e),(f)$, and $(g)$ have been examined for possible relation to the sharply declining and backward turning transonic flutter boundaries observed in Fig. 10. Obviously no backward turning boundaries are predicted here. However, if variations in mass ratio, dynamic pressure level (static aeroelastic deformation), or small changes in Mach number should cause one of the closed flutter regions in Fig. $7(\mathrm{e})$ or (g) to fall below the primary flutter boundary or cause the sharply declining and backward turning $V_{I_{2}}$ mode in Fig. $7(f)$ to fall below or to the right of the primary boundary, then a range of angle of attack and Mach number would exist in which a start, stop, and restart of flutter would occur. This would be consistent with a backward turning boundary as a function of Mach number. In search of these characteristics, extensive calculations have been made for other mass ratios (both higher and lower than 27.41) without indication of the behavior described. Unfortunately, aerodynamic data for the present wing are not available at other Mach numbers between 0.95 and 1.00 .

If the unconventional shapes of the experimentally determined flutter boundaries in Fig. 10 are indeed caused largely by low Reynolds number viscous effects, as previously discussed here and in reference 4 , then it is not surprising that such shapes are not indicated by the present flutter calculations because the aerodynamic parameters used in these calculations were obtained from pressure distributions measured at Reynolds numbers of $2.0 \times$ $10^{6}$ and $3.0 \times 10^{6}$ for $M \geq 0.95$ (Figs. $6(i)$ to $(p)$ ).

The relations between the transonic flutter boundaries calculated with aerodynamic parameters for the two levels of dynamic pressure (Figs. $7(\mathrm{e})$ to $(\mathrm{g})$ ) do, however, offer another explanation for the occurrence of the experimentally observed steeply declining and backward-turning flutter boundaries for nonzero angles of attack (Figs. 10(b) to (d)). Specifically, the aerodynamic effects of static aeroelastic deformation appear to contribute to this behavior. As mentioned previously, the differences in the aerodynamic parameters for the two levels of dynamic pressure at each Mach number (Fig. 6) and the consequent differences in the calculated flutter characteristics (solid and dash curves in Fig. 7) are attributed primarily to differences in static aeroelastic deformations of the aerodynamic model 15 at the two dynamic pressures. Relative to its size, however, the aerodynamic model was two orders of magnitude stiffer in both bending and torsion than the present flutter model. Consequently, the effects of aeroelastic deformation on the aerodynamic parameters and hence on the calculated flutter speeds are substantially lower than they would be for a more flexible model, such as the flutter model. Even so, for the higher Mach numbers and angles of attack the flutter-speed curves calculated with aerodynamic parameters for the two dynamic-pressure levels (solid and dash curves in Fig. 7) differs substantially. 
Consider, for example, the relation between the solid and dash flutter-speed curves in Fig. 7 (e) for $M=0.95$ and $\alpha=2^{0}$ to $3^{\circ}$, condi tions for which Figs. $10(\mathrm{c})$ and (d) show the backward turn of the flutter boundary to be well developed. For these conditions, the lower flutter speed in Fig. 7(e) was calculated with steady-state aerodynamic parameters obtained at the lower dynamic pressure (Fig. 6(i)).

Specifically, the use of aerodynamic parameters for 35 percent lower dynamic pressure reduced the flutter speed by about 8.5 percent and the flutter dynamic pressure by about 16.3 percent. If the aerodynamic model had been more flexible, the indicated fractional change in its test dynamic pressure ( 35 percent) would be expected to cause greater changes in static aeroelastic deformation with greater accompanying changes in the aerodynamic parameters and hence greater differences between the two flutter-speed curves in $\mathrm{Fig} .7(\mathrm{e})$. If the reduction in flutter dynamic pressure were to become as large as the reduction in the "aerodynamic" dynamic pressure, a condition of consistency would exist, and both dynamic-pressure levels would represent valid flutter points at the same Mach number and angle of attack. In other words, a double-valued flutter boundary would be indicated. Thus it is possible that the double-valued backward-turning experimental flutter boundaries in Fig. 10 are caused at least to some extent by changes in static aeroelastic deformation as dynamic pressure and Mach number vary. For comparison, reference 16 shows that backward-turning transonic flutter boundaries can be calculated by use of the HYTRAN2 two-dimensional finitedifference code for the MBB A-3 supercritical airfoil if variations of the static pitch angle with Mach number and dynamic pressure are permitted. No experimental confirmation is provided, however.

\section{Concluding Remarks}

A theoretical and experimental study has been conducted to examine the effects of angle of attack on the transonic flutter characteristics of a highly swept supercritical wing. The steady-state aerodynamic parameters required as input to the modified strip analysis flutter calculations were obtained from published windtunnel pressure distributions. The results indicate that increasing angle of attack from zero can produce substantial changes in the transonic flutter characteristics that are favorable or unfavorable depending on Mach number and angle of attack. The bottom of the transonic flutter-boundary "bucket" is shown to occur at lower Mach number as angle of attack increases. These flutter results correlate wel1, in a qualitative sense, with the well known effects of Mach number and angle of attack on aerodynamic behavior, especially on the development of transonic flow phenomena.

The calculated flutter characteristics are in good agreement with the experimental data at zero angle of attack. At nonzero angles of attack, however, the experiments show sharply declining and backward-turning transonic flutter boundaries that are not indicated by the calculations. Published information indicates that such unconventional flutter boundaries may be caused by viscous effects at low Reynolds number which were not represented in the present calculations because the aerodynamic data available for use in the calculations were for much higher Reynolds numbers than the flutter data. The present investigation indicates, however, that the ocurrence of the unconventional transonic boundaries may be caused, at least to some extent, by variations in static aeroelastic deformation.

\section{References}

1Farmer, Moses G.; Hanson, Perry W.; and Wynne, Eleanor C.: Comparison of Supercritical and Conventional Wing Flutter Characteristics. NASA TM-72837, 1976.

2McGrew, J. A.; Giesing, J. P; Pearson, R. M.; Zuhurudding, K.; Schmidt. M. E.; and Kalman, T. P.: Supercritical Wing Flutter, AFFDL-TR-78-37, 1978.

3 Yates, E. Carson, Jr.: Wynne, Eleanor C.; Farmer, Moses G.; and Desmarais, Robert N.: Prediction of Transonic Flutter for a Supercritical Wing by Modified Strip Analysis and Comparison with Experiment. AIAA Paper No. $81-0609,1981$.

4Houwink, R.; Kraan, A. N.; and Zwaan, R. J.: A Wind-Tunnel Study of the Flutter Characteristics of a Supercritical Wing. AIAA paper No. 81-0651, 1981 .

5yates, E. Carson, Jr.: Calculation of Flutter Characteristics for Finite-Span Swept or Unswept Wings at Subsonic and Supersonic Speeds by a Modified Strip Analysis, NACA RM L57L10, 1958.

6rates, E. Carson, Jr.: Modified-StripAnalysis Method for Predicting Wing Flutter at Subsonic to Hypersonic Speeds. J. Aircraft, Vol. 3, No. 1, February 1966.

7 Yates, E. Carson, Jr.: Use of Experimental Steady-Flow Aerodynamic Parameters in the Calculation of Flutter Characteristics for Finite-Span Swept or Unswept Wings at Subsonic, Transonic, and Supersonic Speeds, NASA TM X-183, 1959.

8Yates, E. Carson, Jr.; and Bennett, Robert $M_{.}:$Use of Aerodynamic Parameters from Nonlinear Theory in Modified-Strip-Analys is Flutter Calculations for Finite-Span Wings at Supersonic Speeds, NASA TN D-1824, 1963.

9Yates, E. Carson, Jr.: Subsonic and Supersonic Flutter Analysis of a Highly Tapered Swept-Wing Planform, Including Effects of Density Variation and Finite Wing Thickness, and Comparison with Experiments. NASA TN D-4230, 1967.

10Yates, E. Carson, Jr.; and Bennett, Robert $M_{0}$ : Analysis of Supersonic-Hypersonic Flutter of Lifting Surfaces at Angle of Attack. J. Aircraft, Vol. 9, No. 7, July 1972, pp. 481 489. 
11 Yates, E. Carson, Jr.: Flutter and Unsteady-Lift Theory. In "Performance and Dynamic of Aerospace Vehicles." NASA SP-258, 1971.

12De Vries, G.: Sondage des Systêms Vibrants par Massess Additionnelles. Rech. Aéronaut., No. 30, Nov.-Dec. 1952, pp. 47-49.

13Theodorsen, Theodore: General Theory of Aerodynamic Instability and the Mechanism of Flutter. NACA Rep. 496, 1935.

14Jordan, P. F.: Aerodynamic Flutter Coefficients for Subsonic, Sonic and Supersonic Flow (Linear Two-Dimensional Theory). R. \& M. No. 2932, British A.R.C., 1957.

15Harris, Charles D.: Wind-Tunnel Investigation of the Aerodynamic Load Distribution of a Supercritical Wing Research Airplane Configuration. NASA TM X-2469, 1972.

16Edwards, John W.; Bennett, Robert M.; Whitlow, Woodrow, Ir.: and Seidel, David A.: Time-Marching Transonic Flutter Solutions Including Angle-of-Attack Effects. AIAA Paper No. $82-0685,1982$.

17 Sandford, Maynard C.; Ruhlin, Charles L.; and Abel, Irving: Flutter Studies of Simplified Component Models of a Vartable-SweepWing Airplane at Mach Numbers Up to 3.0. NASA TN D-3501, 1966.

18Ashley, H.: Role of Shocks in the "Sub-Transonic" Flutter Phenomenon. J. Aircraft, Vol. 17, No. 3, March 1980, pp. 187-197.

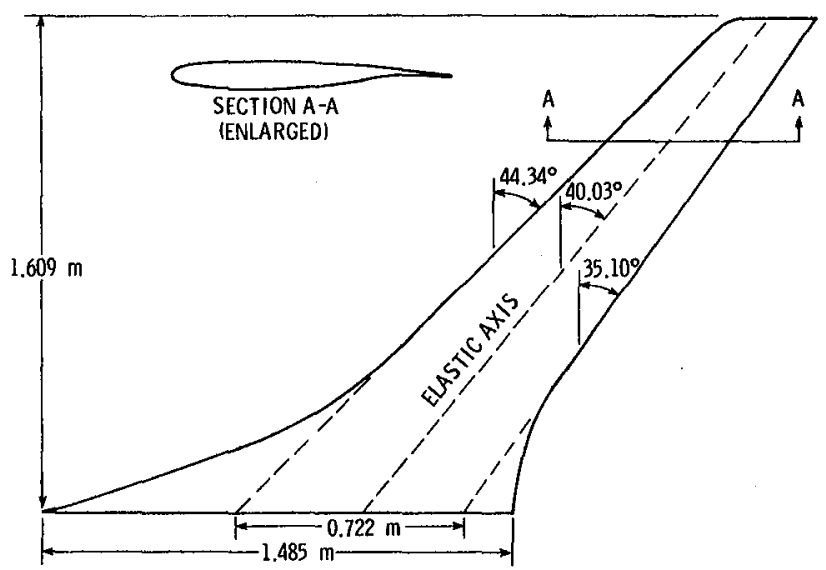

(a) Wing planform.

Fig. 1 Supercritical wing flutter model.

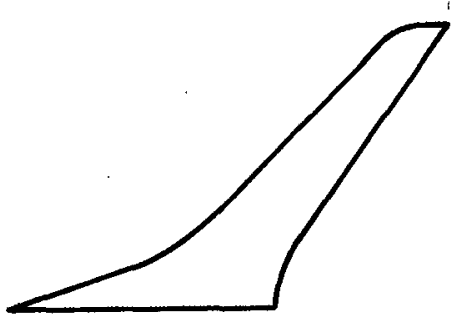

MODE $1,33.24 \mathrm{rad} / \mathrm{sec}$

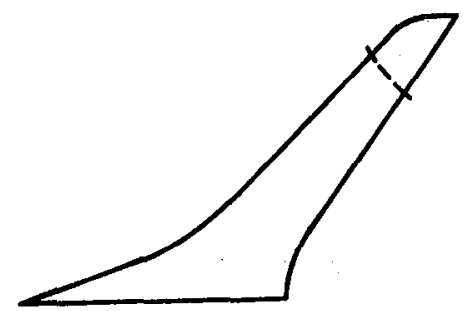

MODE 2, $113.6 \mathrm{rad} / \mathrm{sec}$

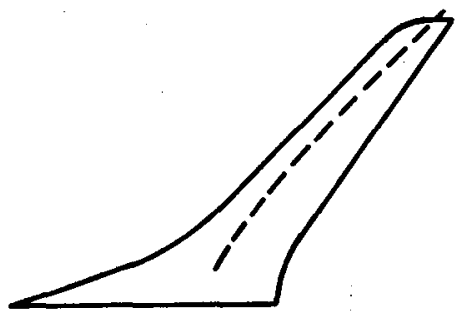

MODE 3, 233.1 rad/ $\mathrm{sec}$

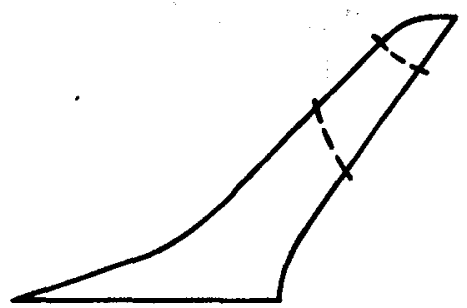

MODE 4, $268.9 \mathrm{rad} / \mathrm{sec}$

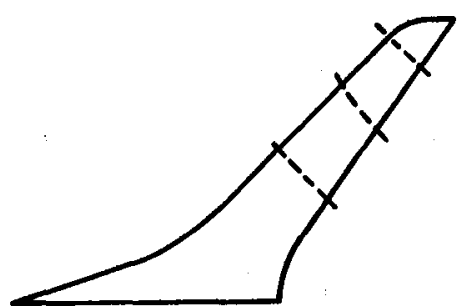

MODE 5, $461.2 \mathrm{rad} / \mathrm{sec}$

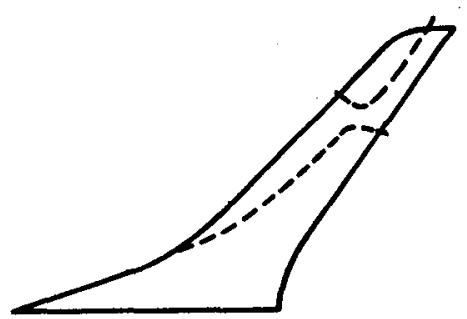

MODE 6, $466.8 \mathrm{rad} / \mathrm{sec}$

(b) Node lines of measured vibration modes.

Fig. 1 Concluded. 


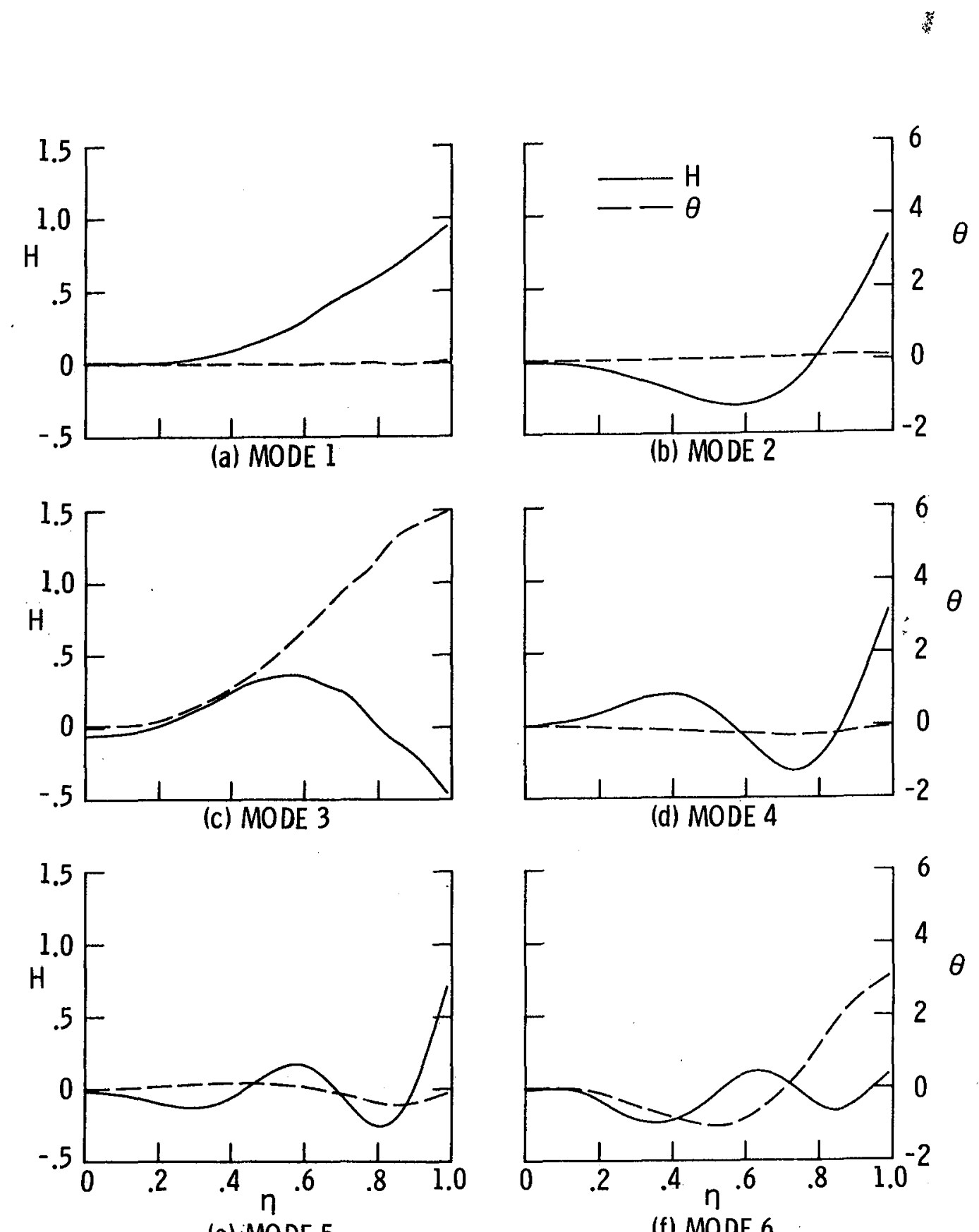

(e) MODE 5

(f) MODE 6

Fig. 2 Bending and torsional components of measured natural vibration modes. 


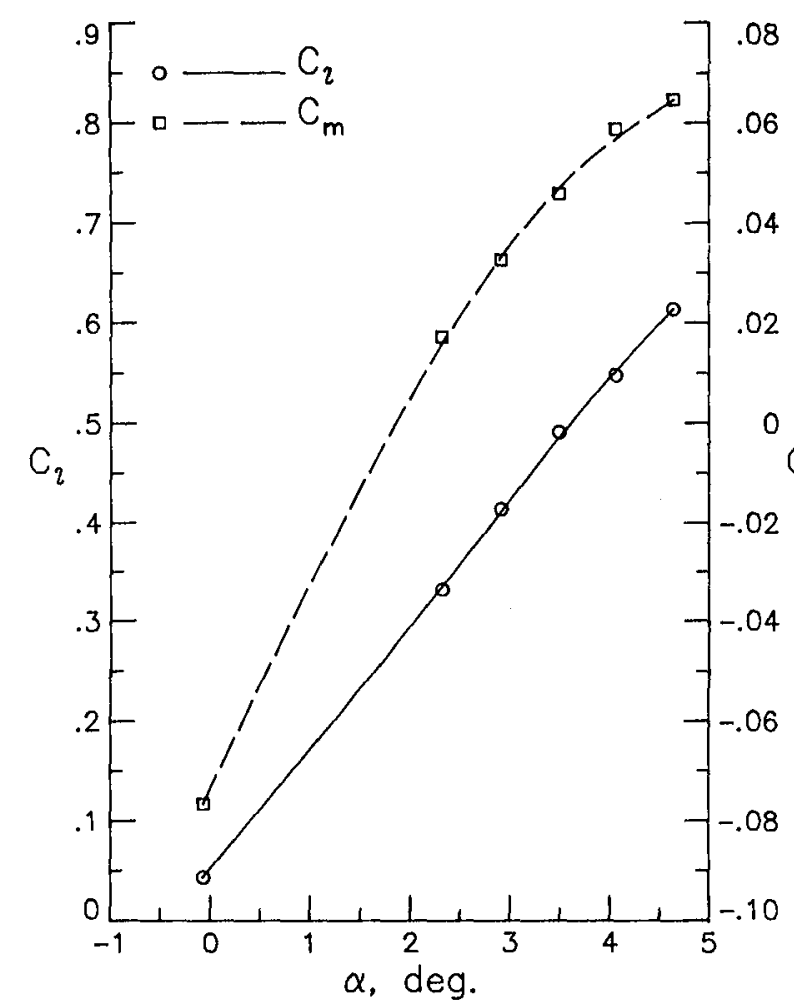

(a) $\eta=.5125$

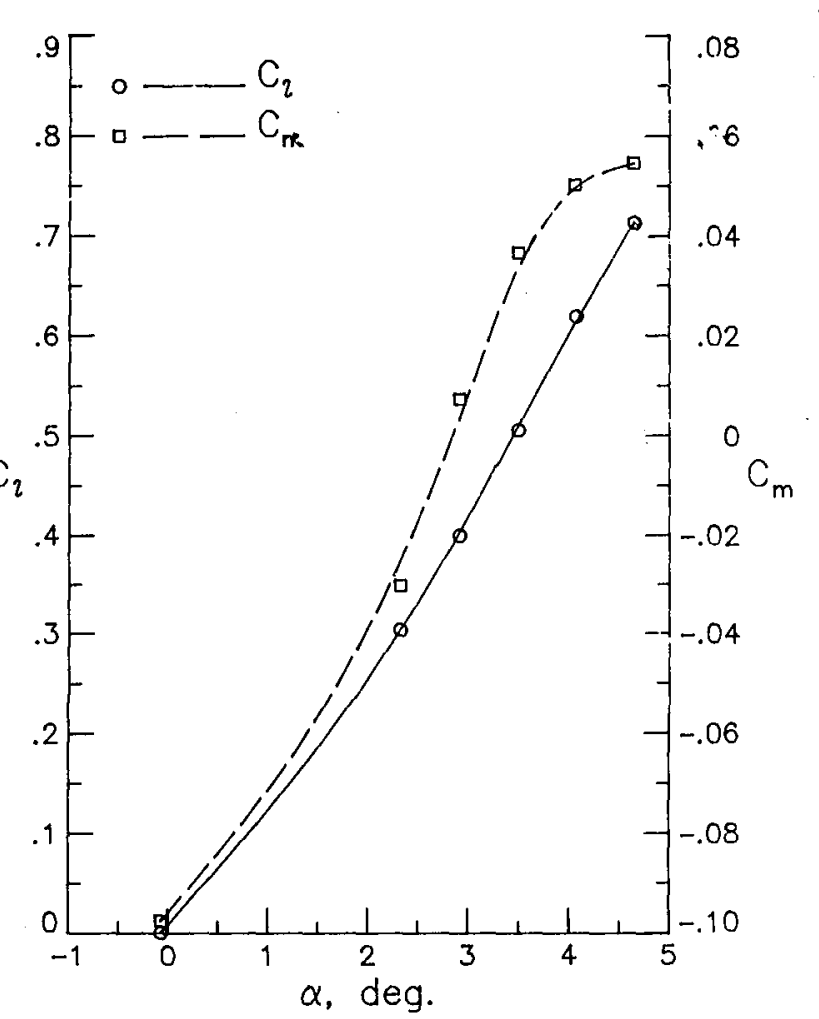

(b) $\eta=.7625$

Fig. 3 Typical section aerodynamic coefficients for $M=0.95, q=28.7 \mathrm{kPa}$.

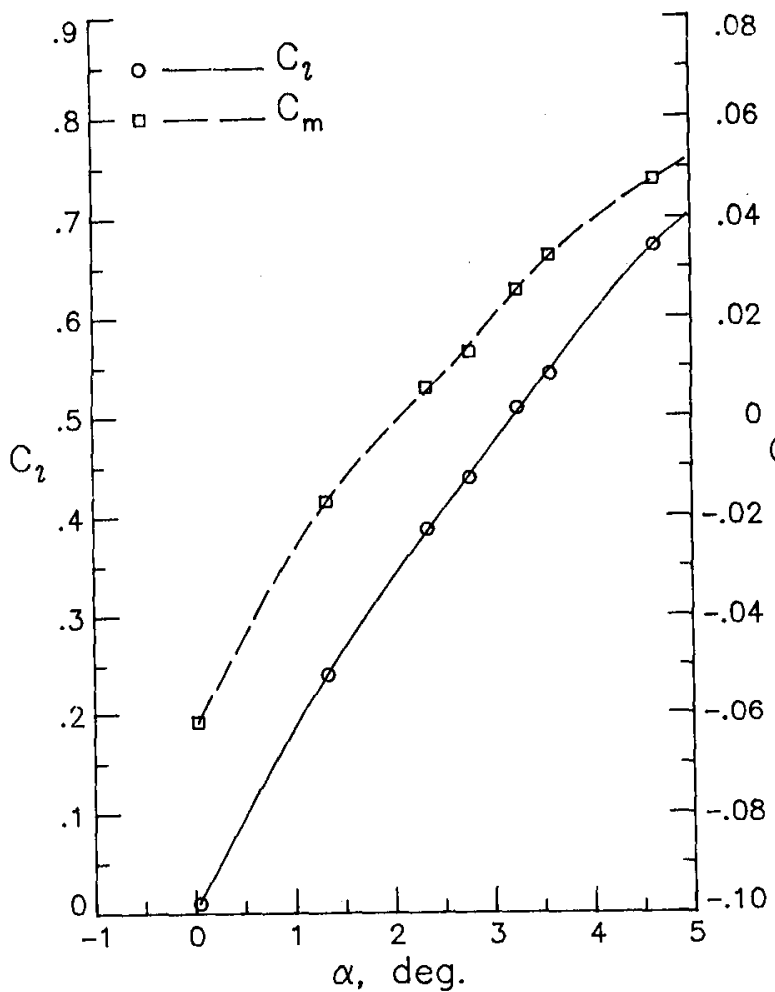

(a) $\eta=.5125$

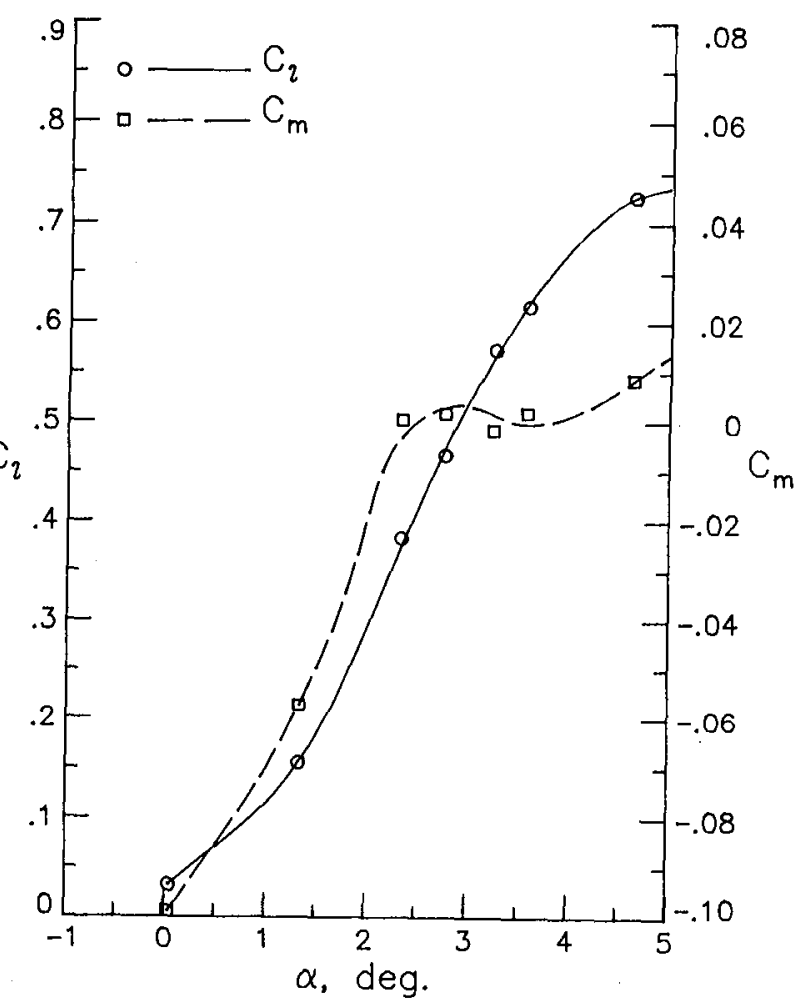

(b) $\eta=.7625$

Fig. 4 Typical section aerodynamic coefficients for $M=0.99, q=28.7 \mathrm{kPa}$. 


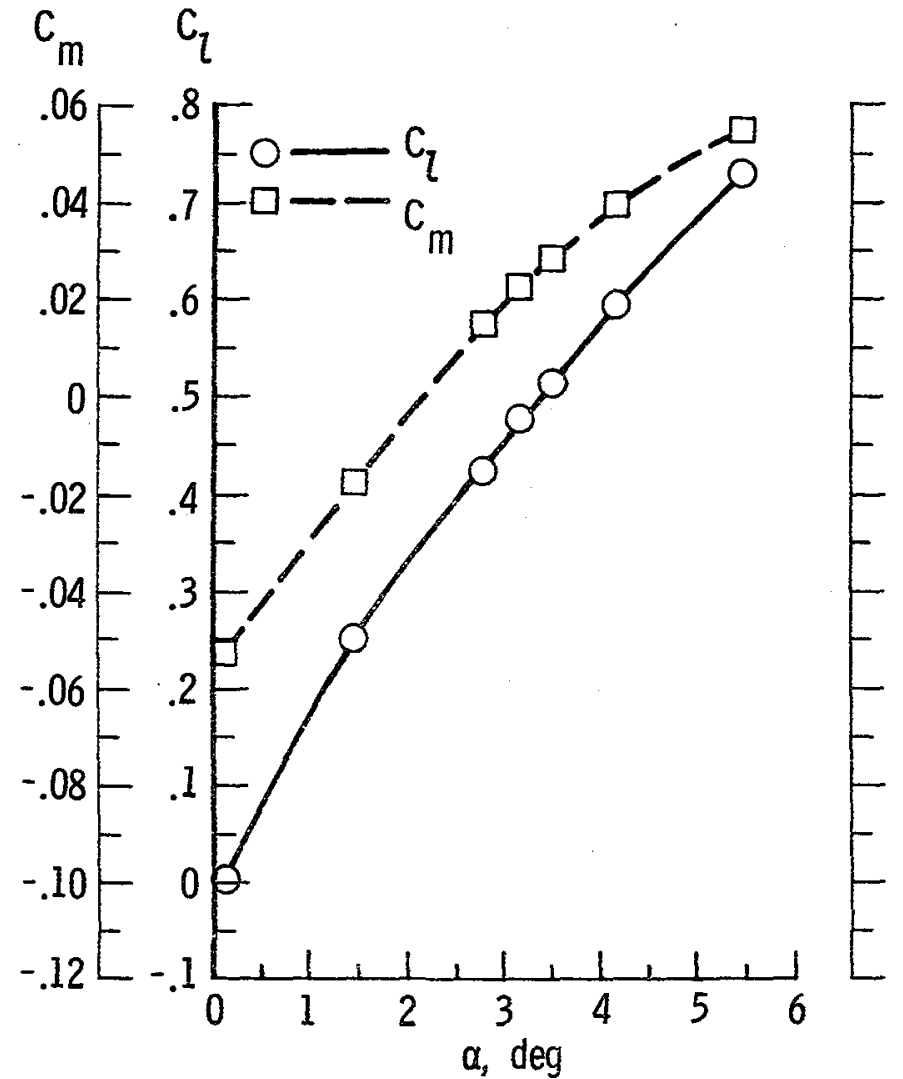

(a) $n=.5125$

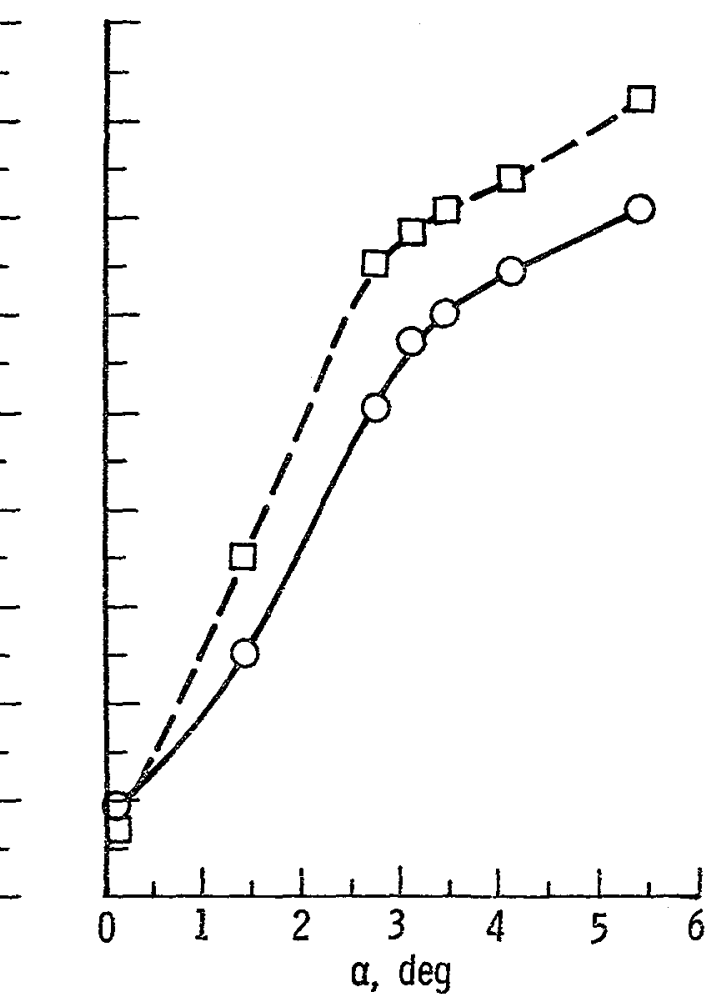

(b) $\eta-.7625$

Fig. 5 Typical section aerodynamic coefficients for $M=0.99, q=44.2 \mathrm{kPa}$. 


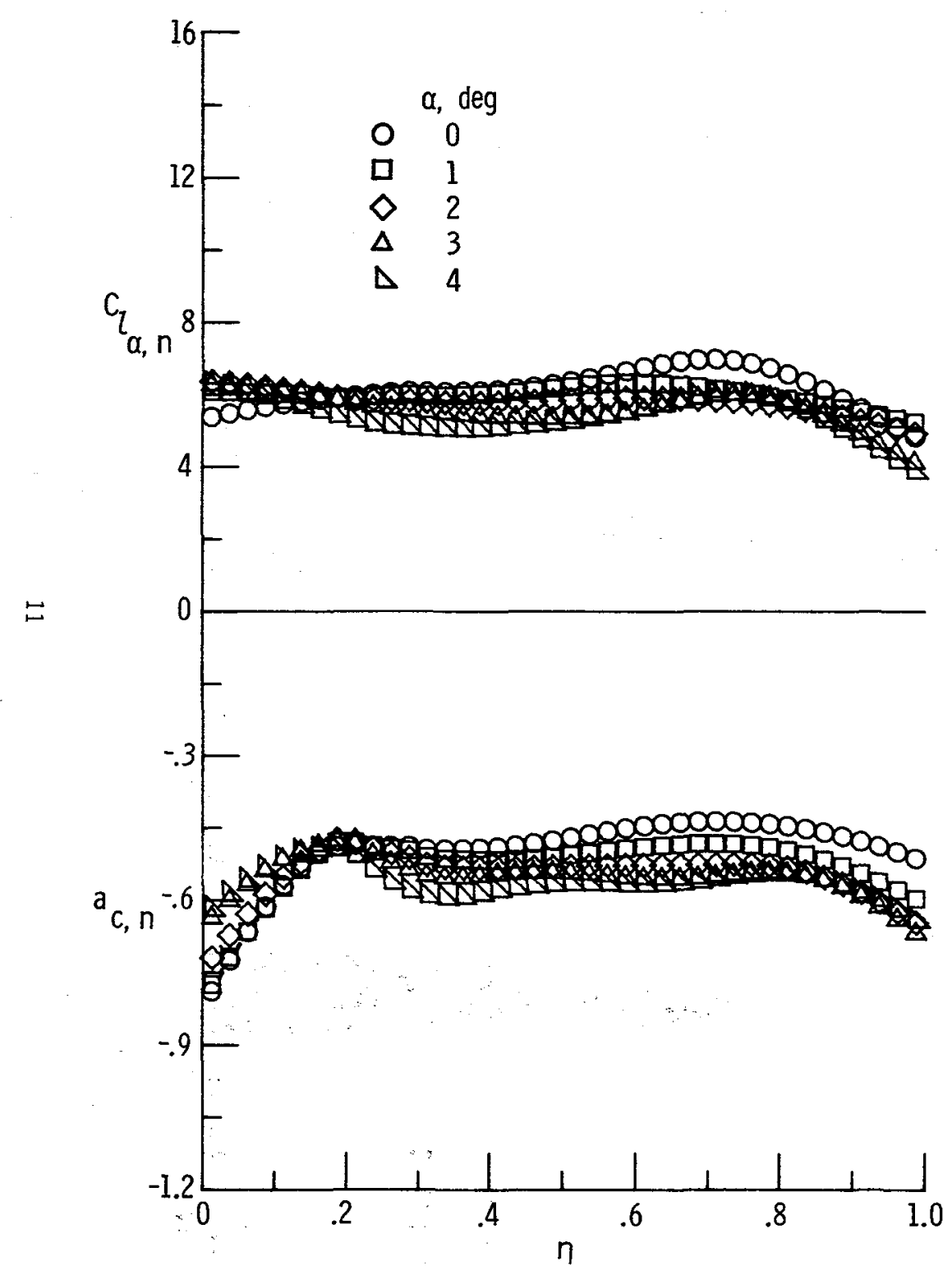

(a) $M=.25, q=5.51 \mathrm{kPa}$

Fig. 6 Aerodynamic Parameters for Flutter Analys is.
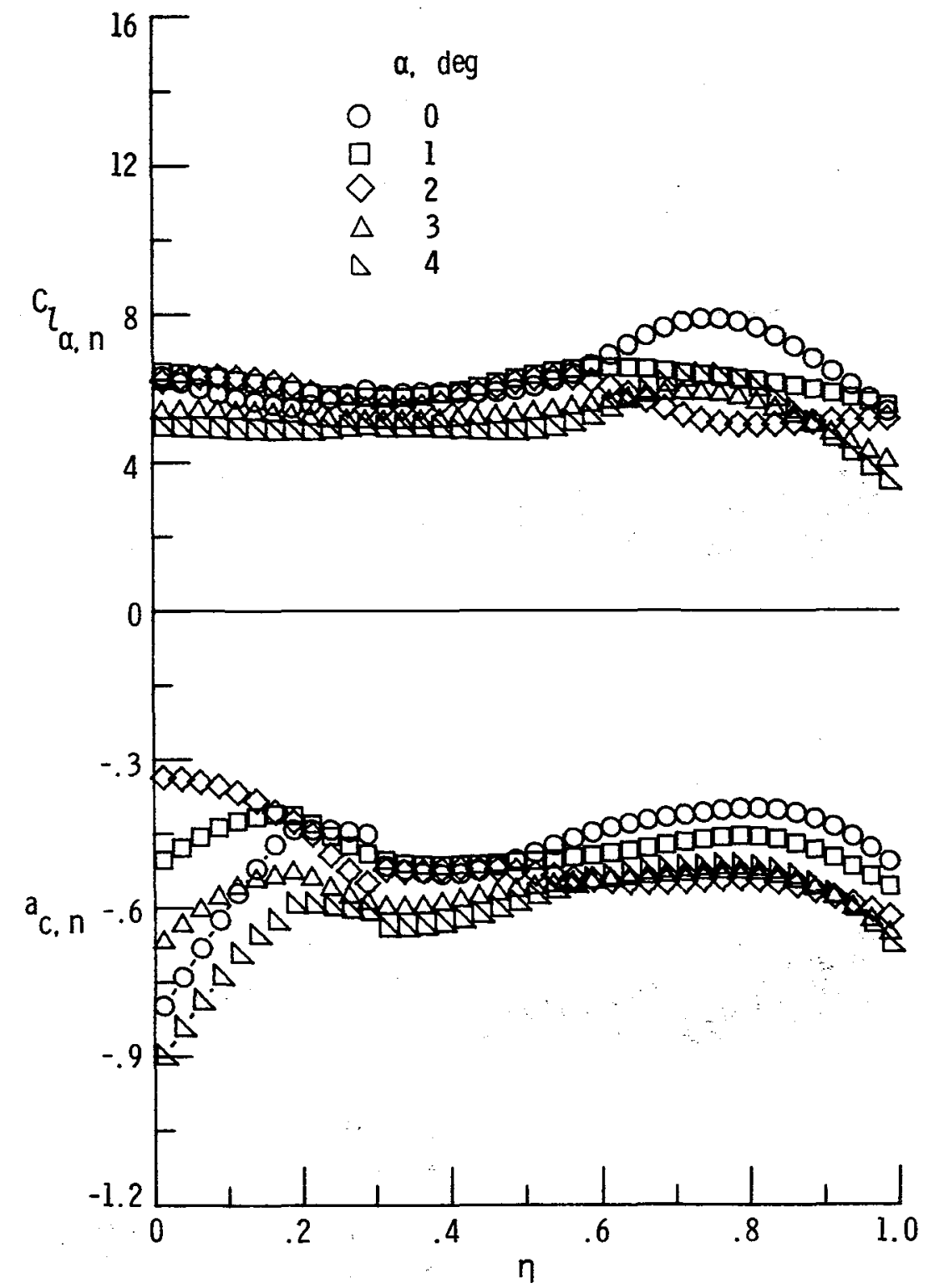

(b) $M=.25, q=8.52 \mathrm{kPa}$

Fig. 6 continued. 


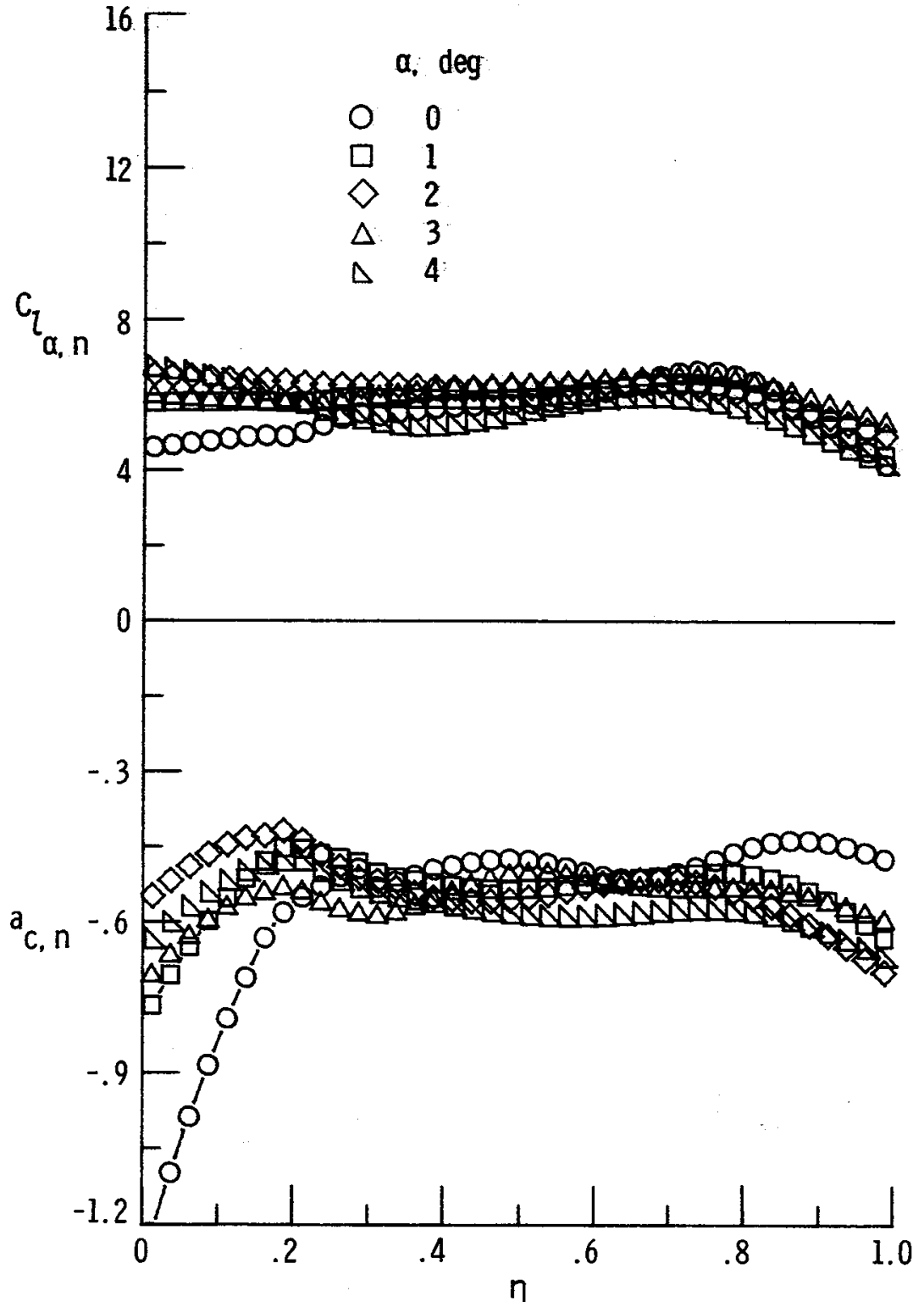

(c) $\mathrm{M}=.50, \mathrm{q}=15.6 \mathrm{kPa}$

Fig. 6 Continued.

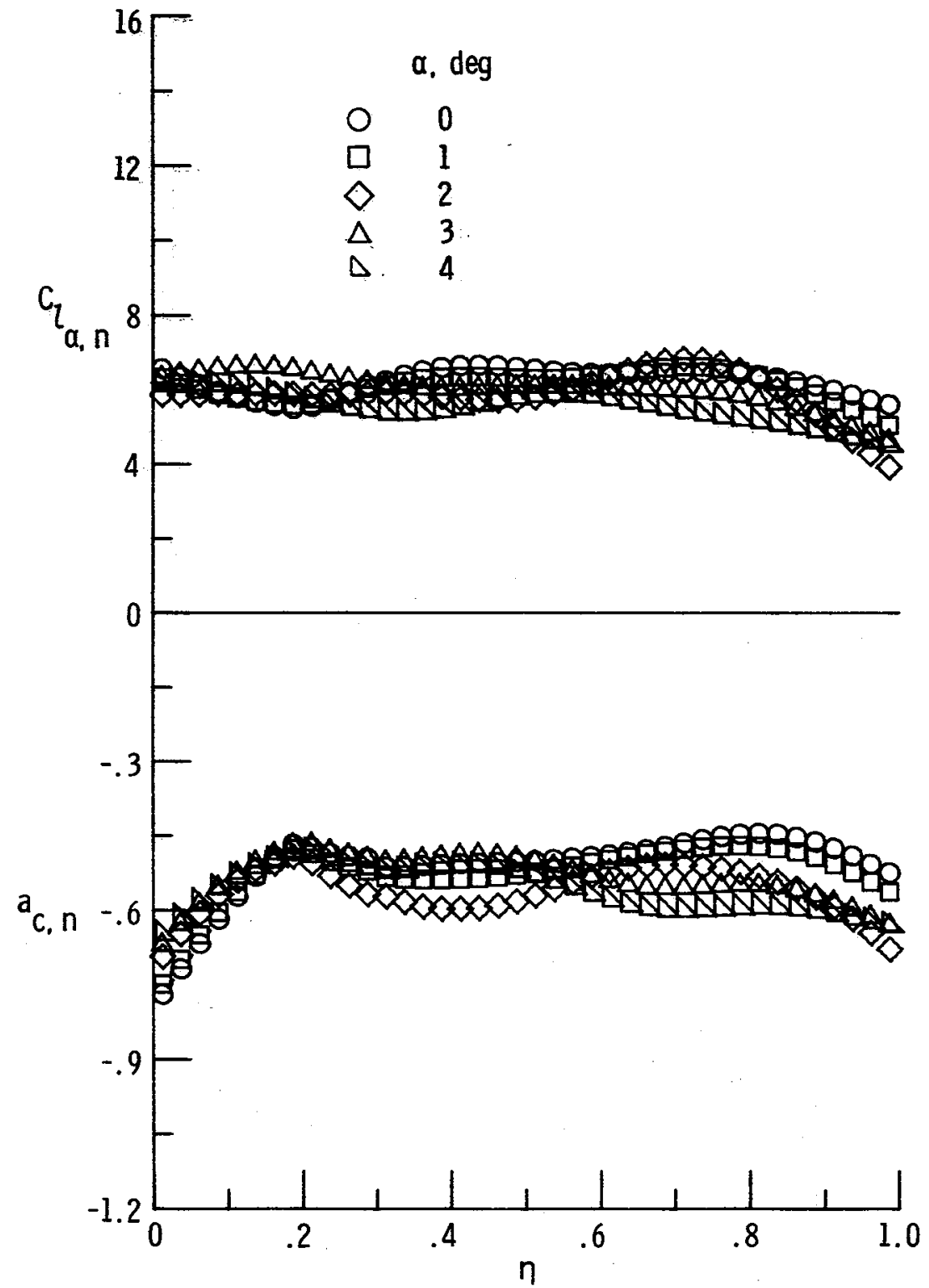

(d) $M=.50, q=23.9 \mathrm{kPa}$

Fig. 6 Continued. 


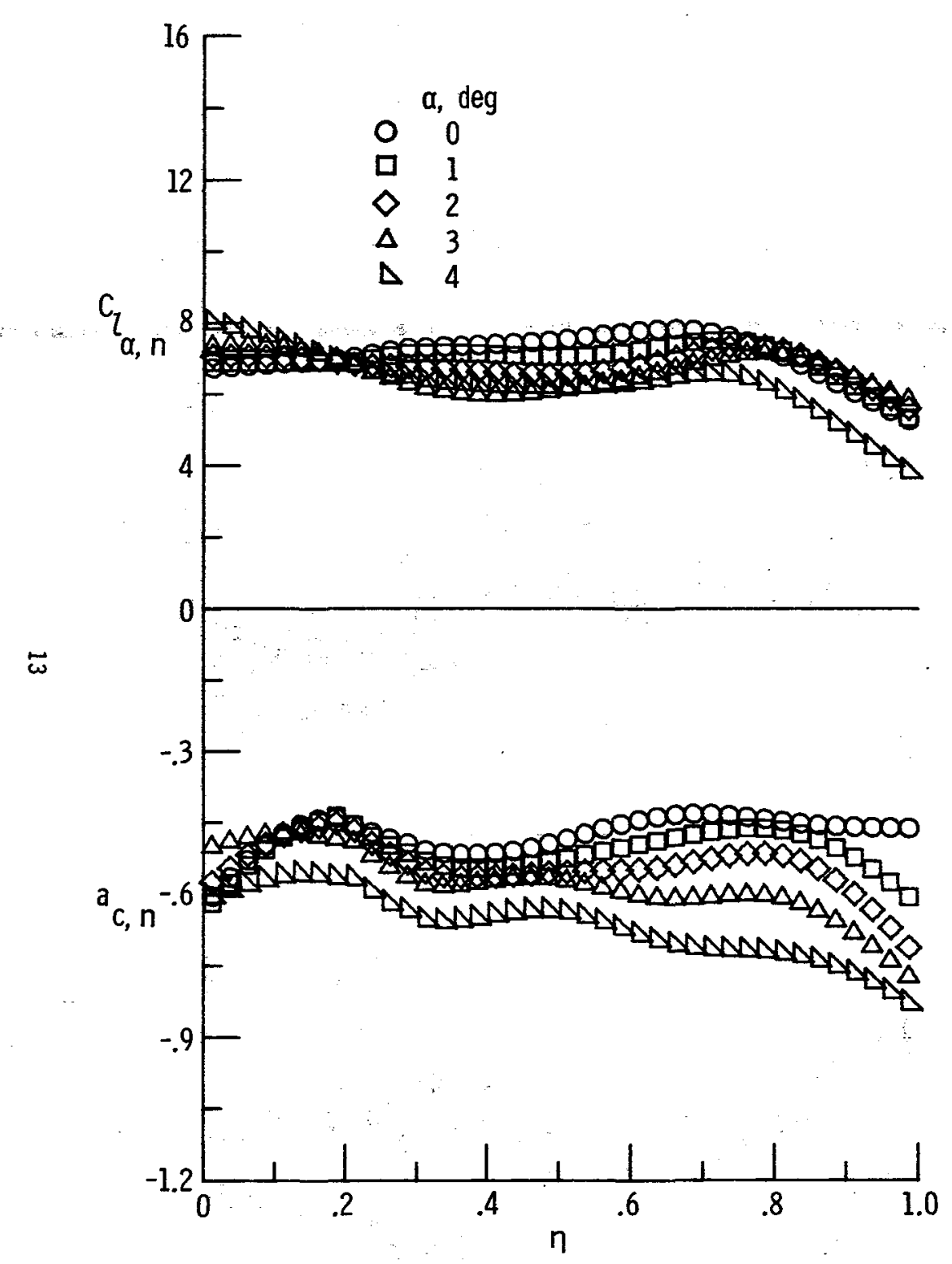

(e) $M=.80, q=31.1 \mathrm{kPa}$

Fig. 6 Continued.

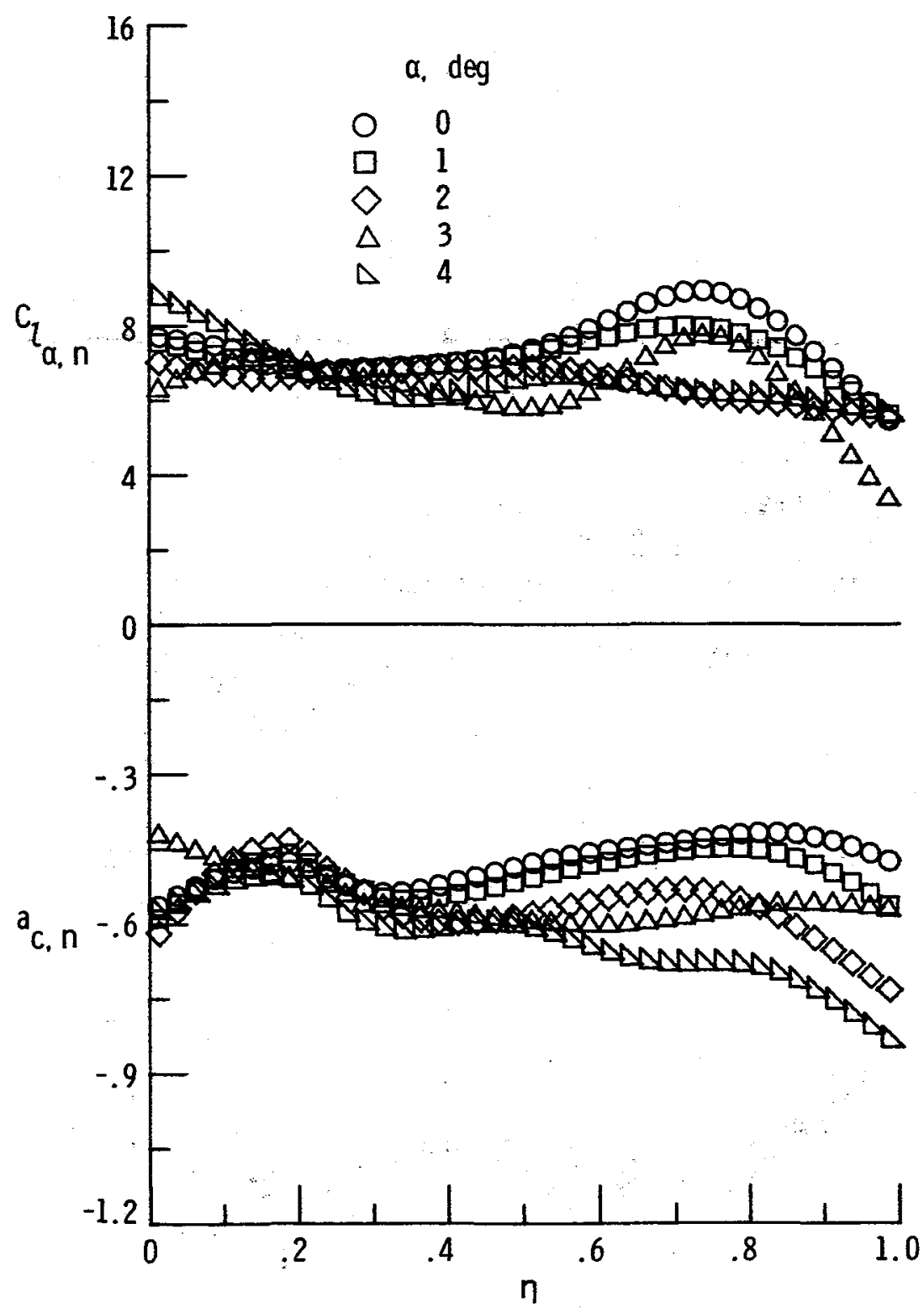

(f) $M=.80, q=47.9 \mathrm{kPa}$

Fig. 6 Continued. 


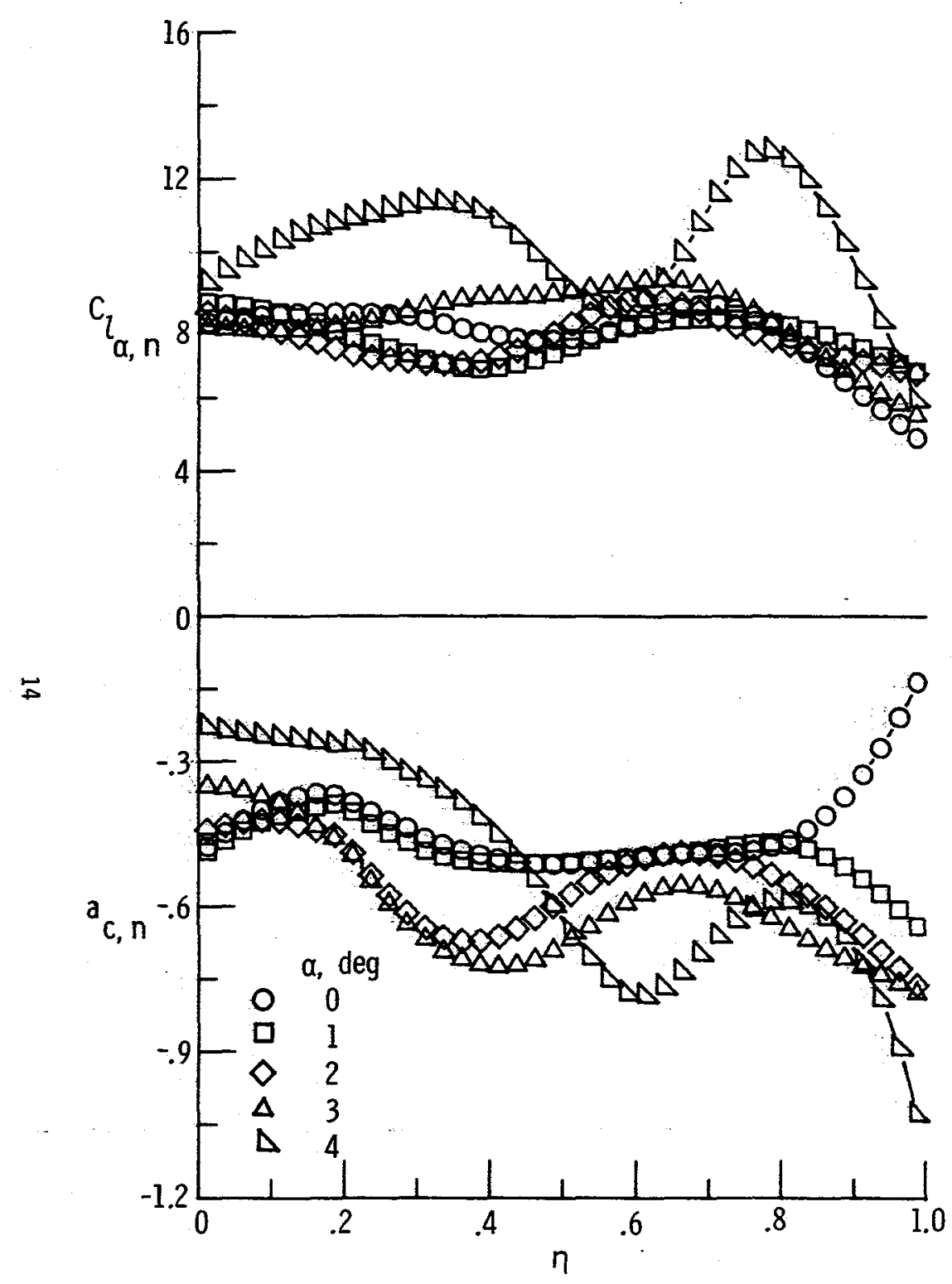

(g) $M=.90, q=31.1 \mathrm{kPa}$

Fig. 6 Continued.

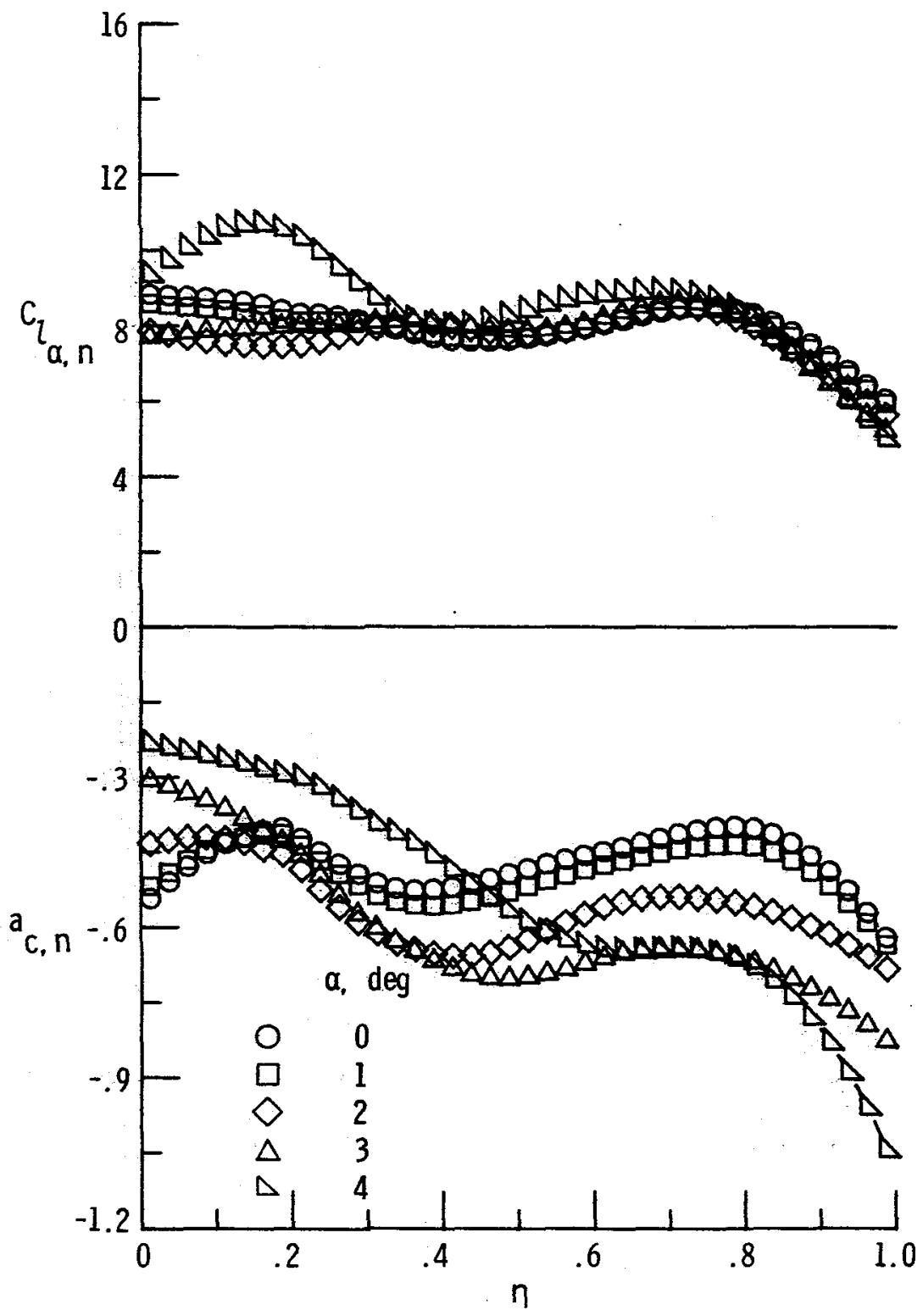

(h) $M=.90, q=47.9 \mathrm{kPa}$

Fig. 6 Continued. 


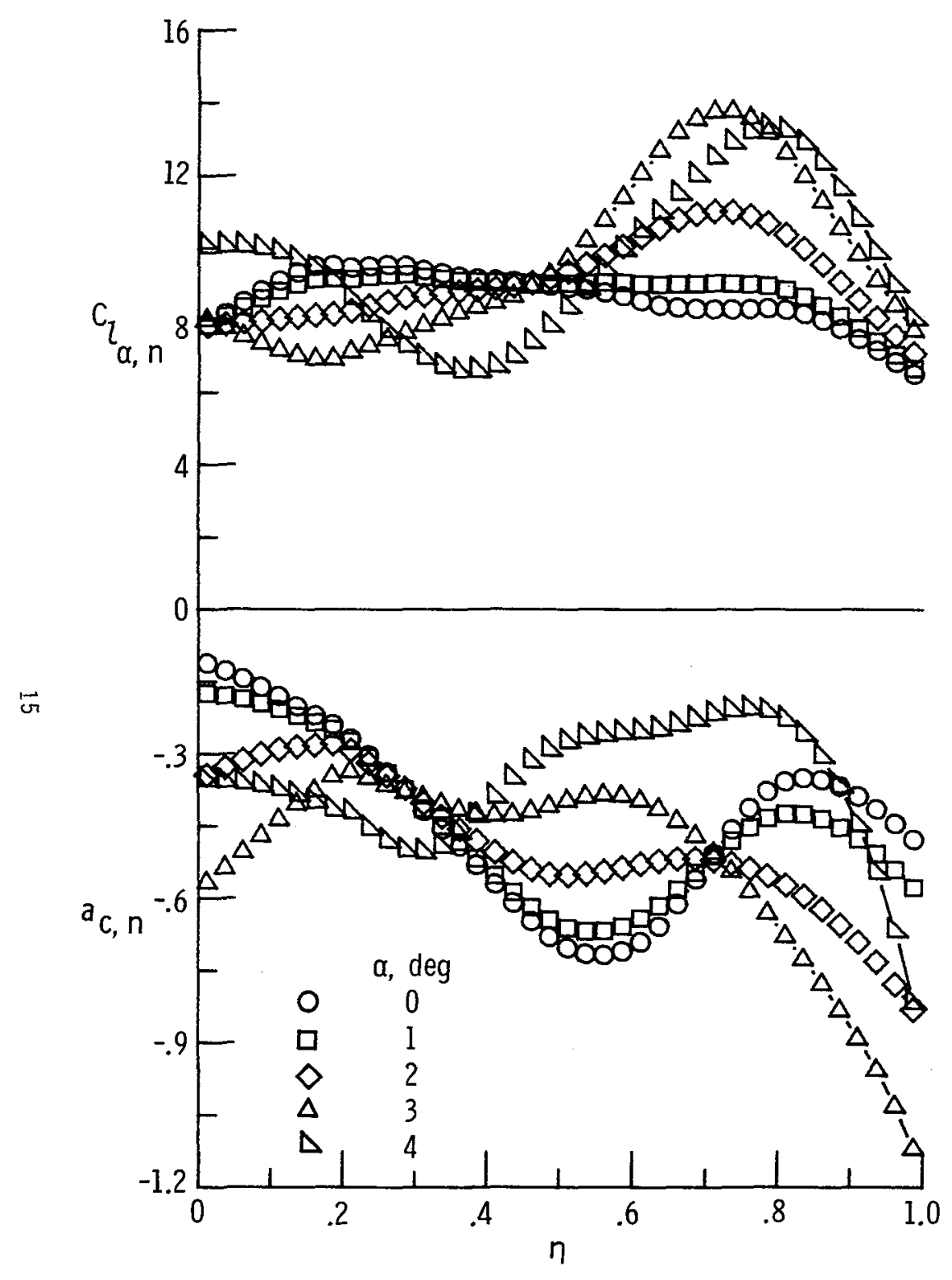

(i) $M=.95, q=28.7 \mathrm{kPa}$

Fig. 6 Continued.

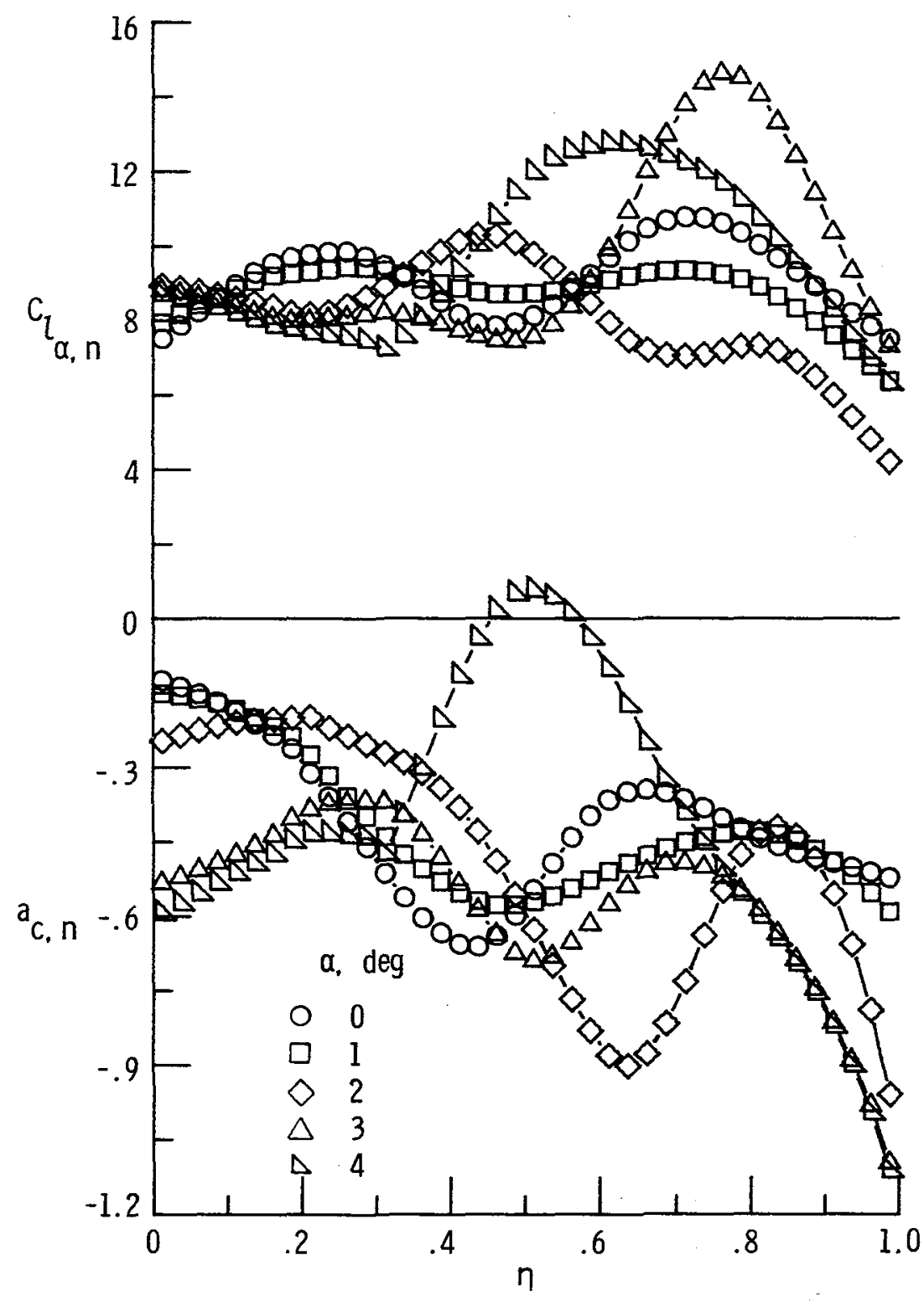

(j) $M=.95, q=44.2 \mathrm{kPa}$

Fig. 6 Continued. 


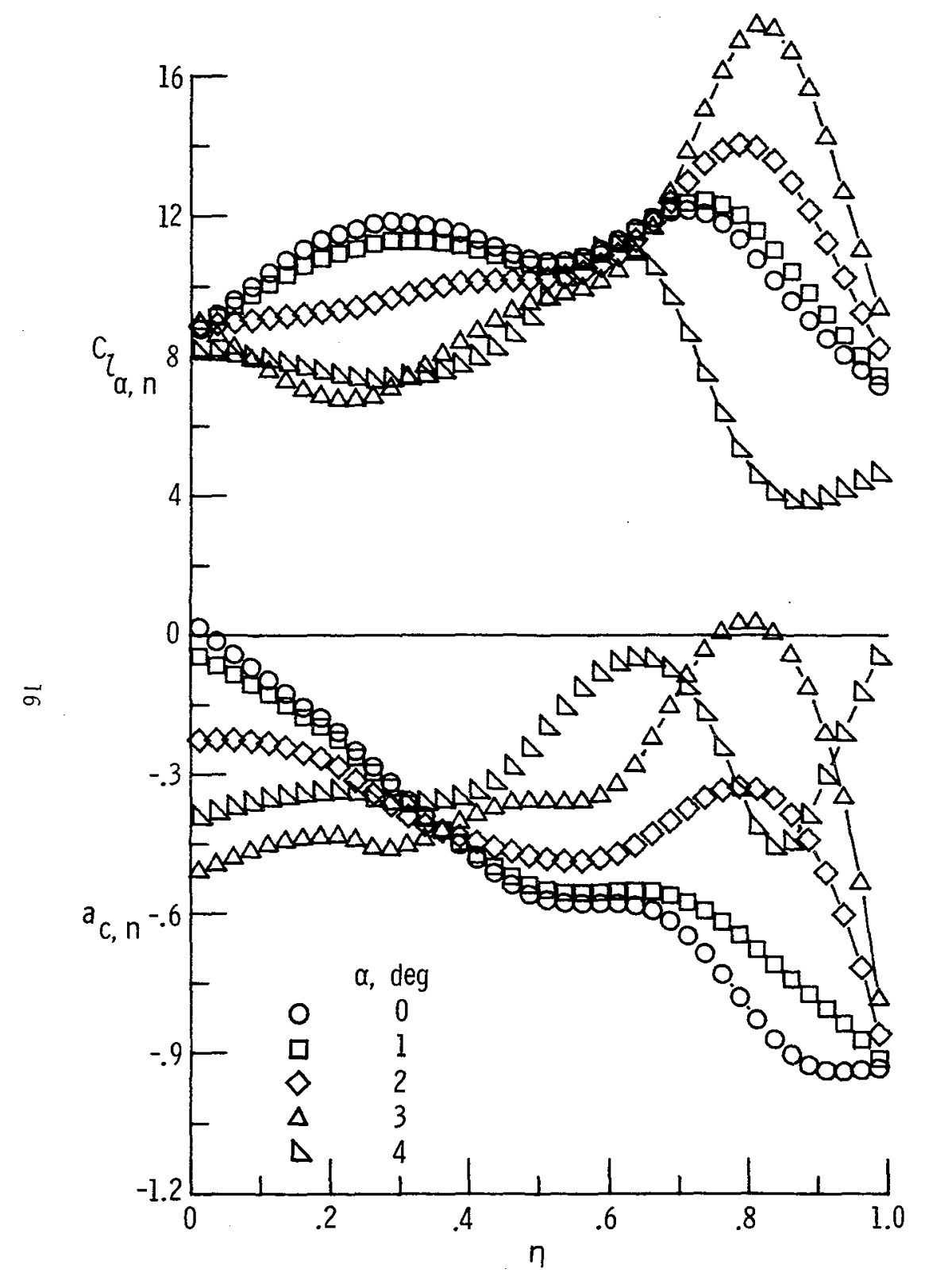

(k) $M=.98, q=28.7 \mathrm{kPa}$

Fig. 6 Continued.

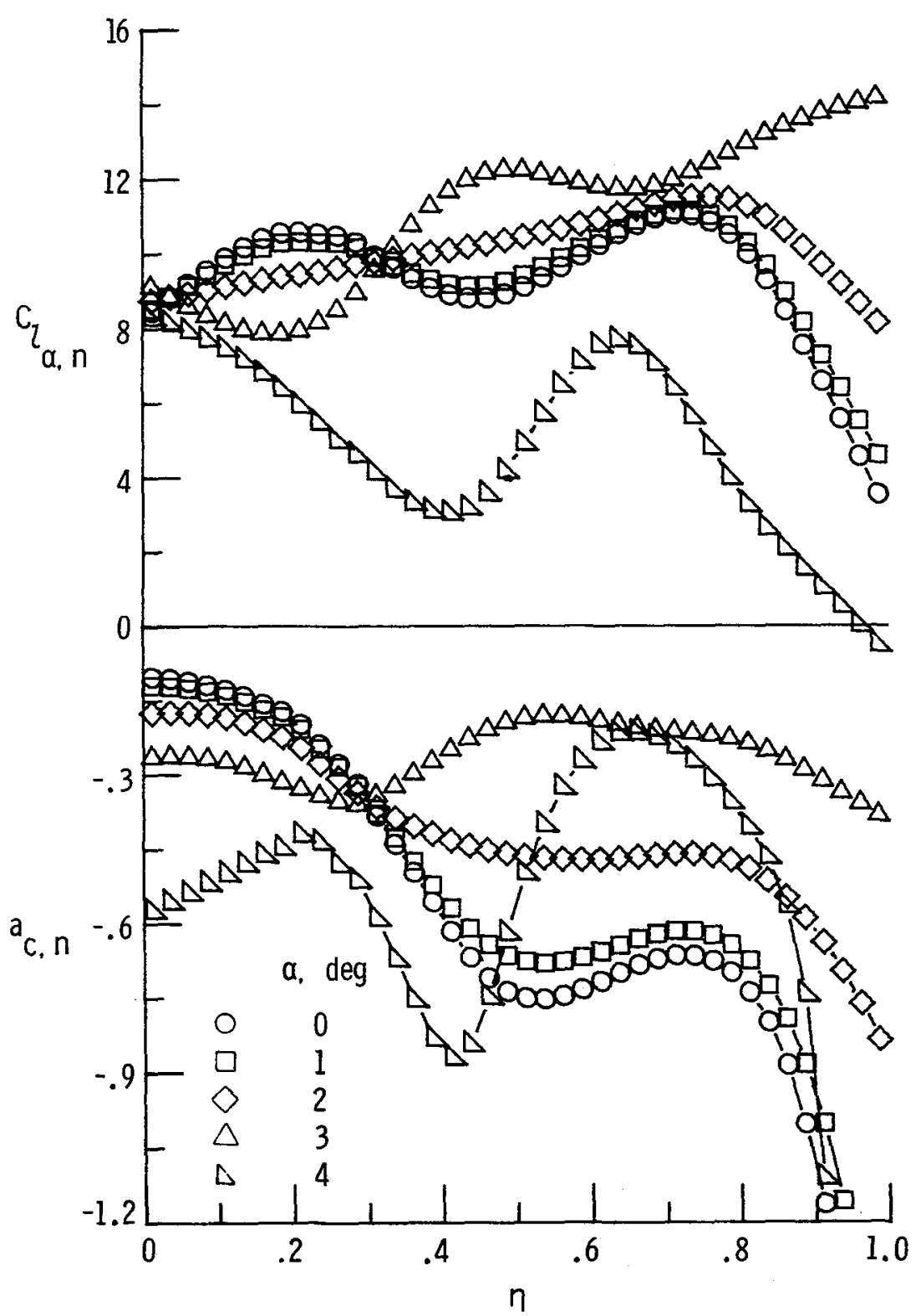

(1) $M=.98, q=44.2 \mathrm{kPa}$

Fig. 6 Continued. 


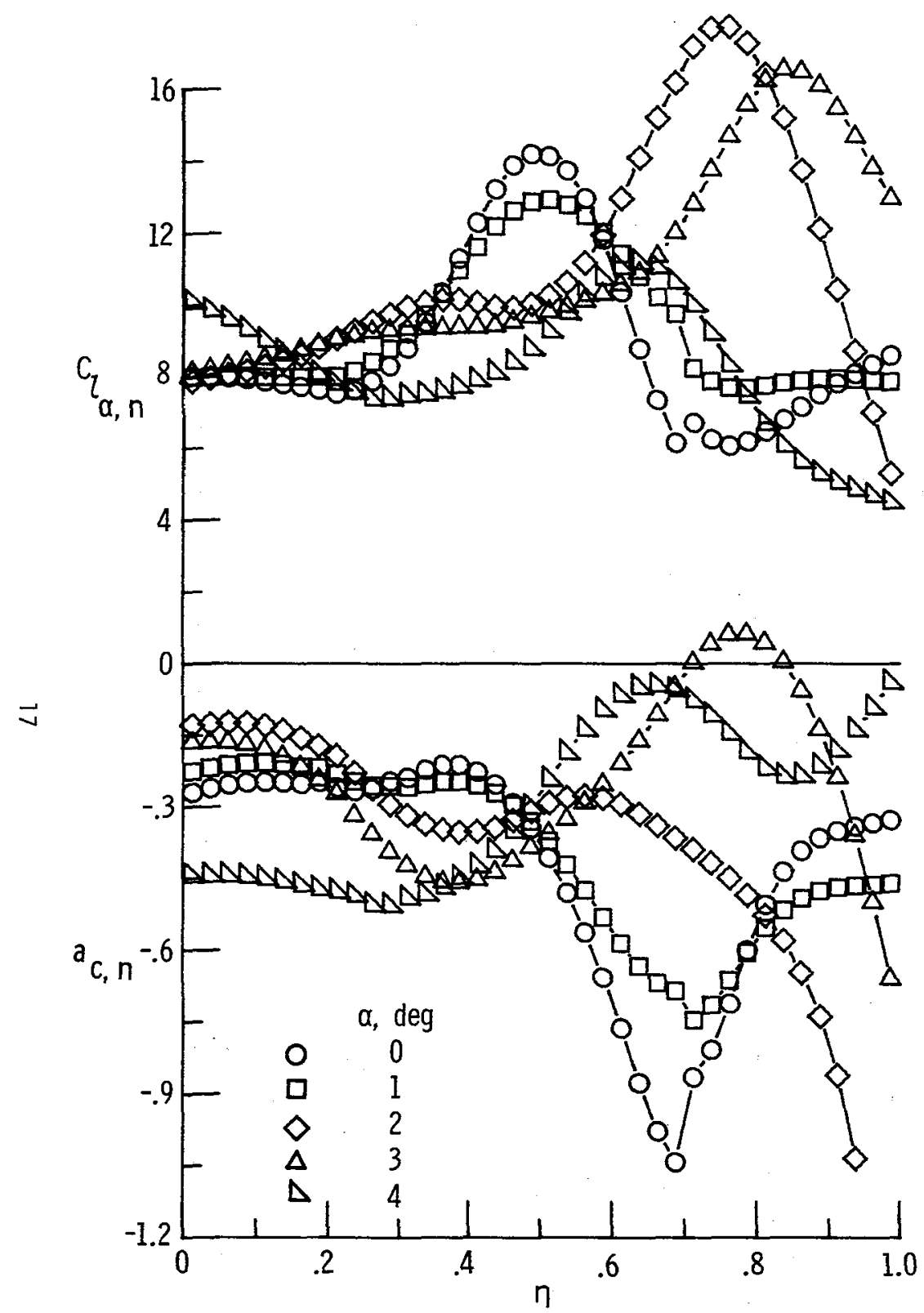

(m) $M=.99, q=28.7 \mathrm{kPa}$

Fig. 6 Continued.

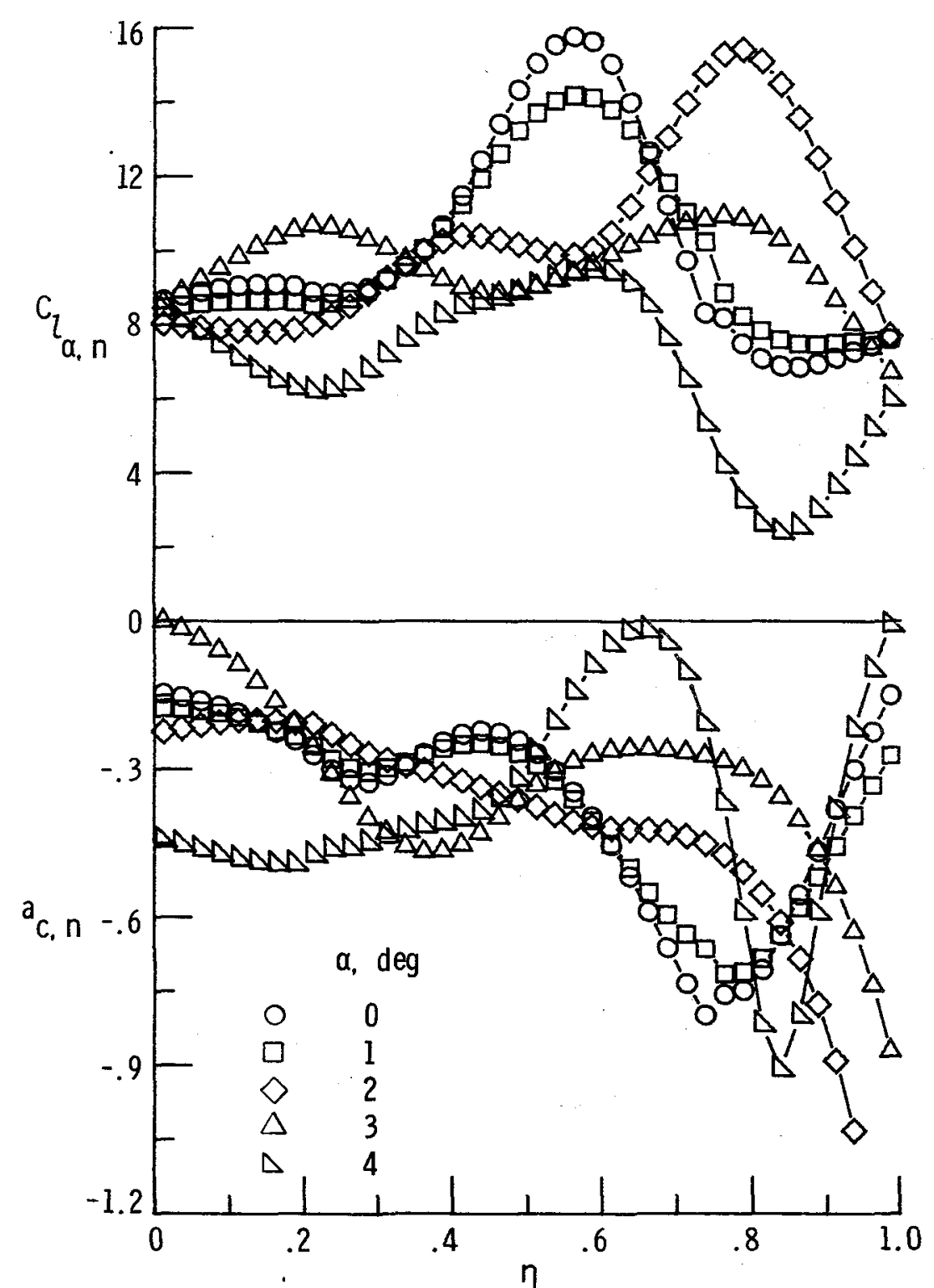

(n) $M=.99, q=44.2 \mathrm{kPa}$

Fig. 6 Continued. 


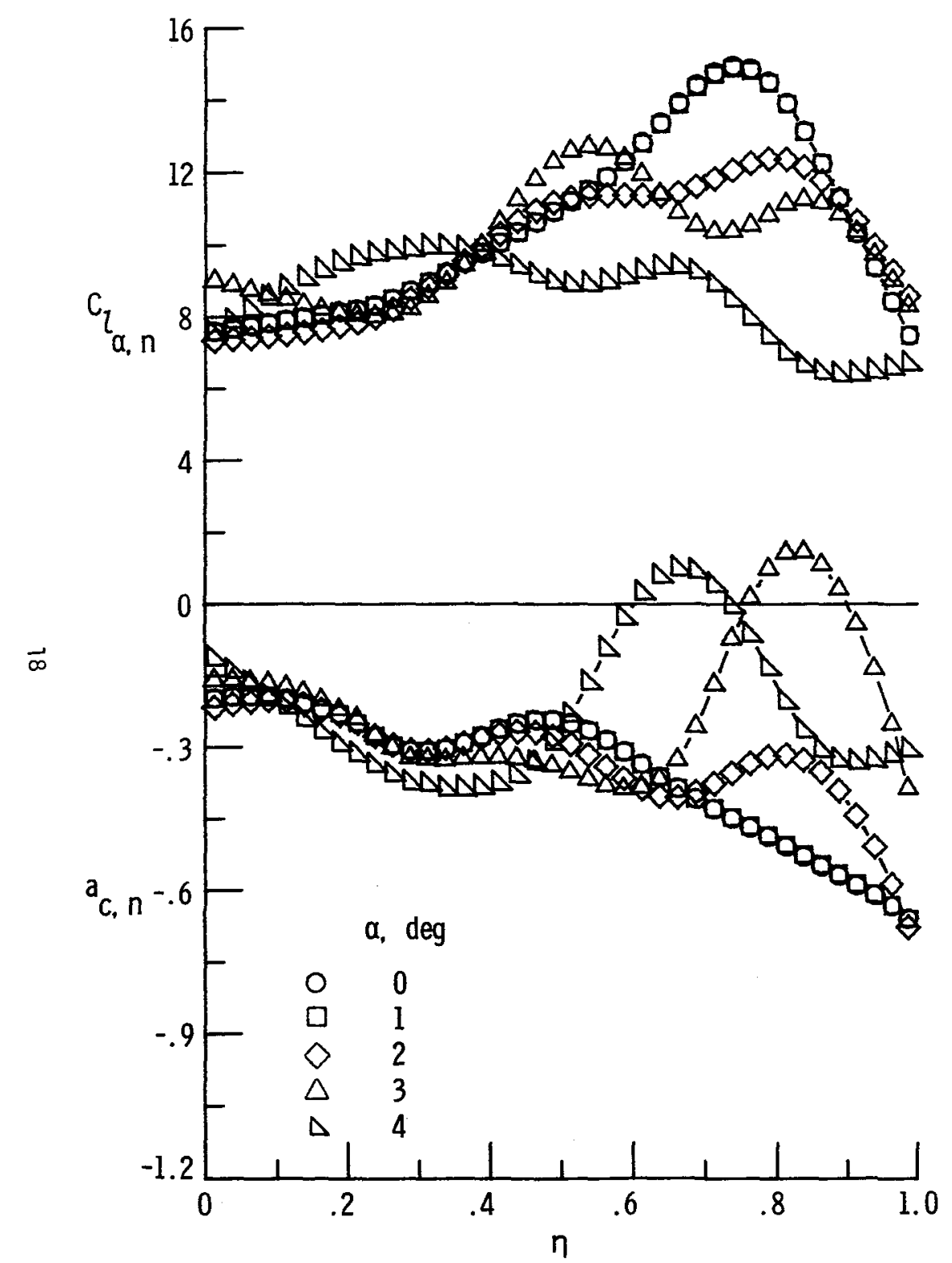

(o) $M=1.00, q=28.7 \mathrm{kPa}$

Fig. 6 Continued.

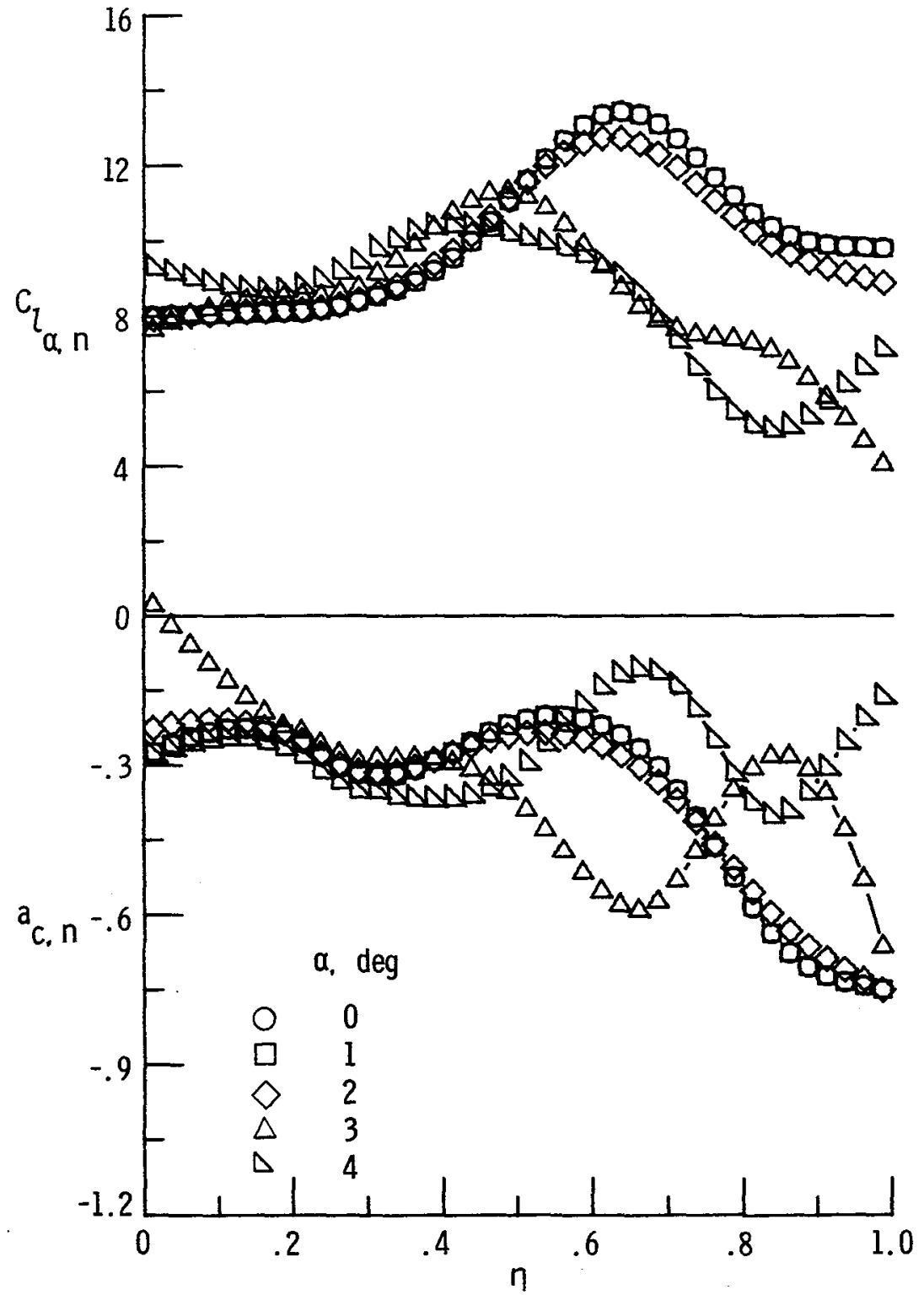

(p) $M=1.00, q=44.2 \mathrm{kPa}$

Fig. 6. Concluded. 


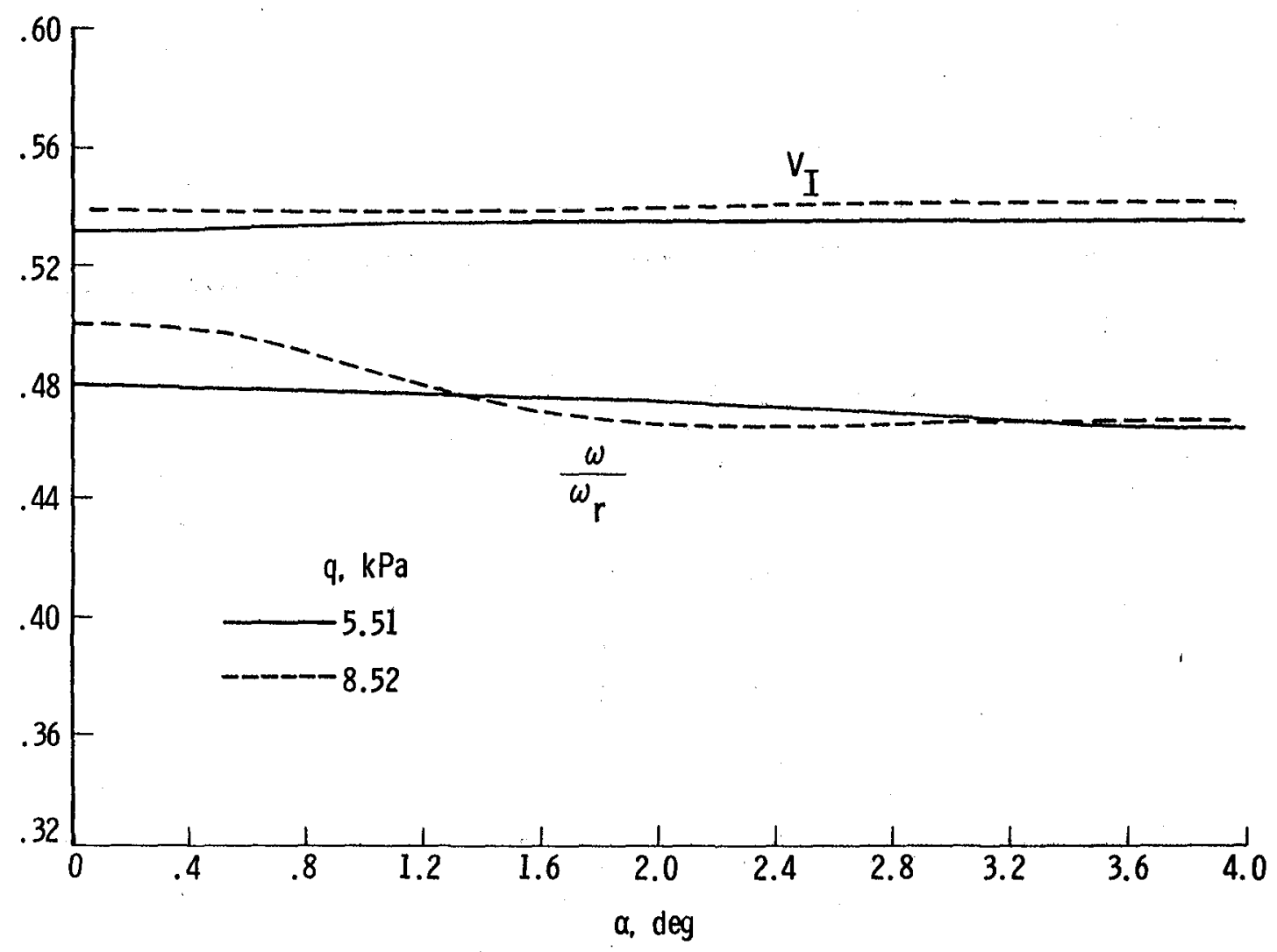

(a) $M=0.25$

Fig. 7 Effect of Angle of Attack on Flutter. $\mu_{r}=27.41$

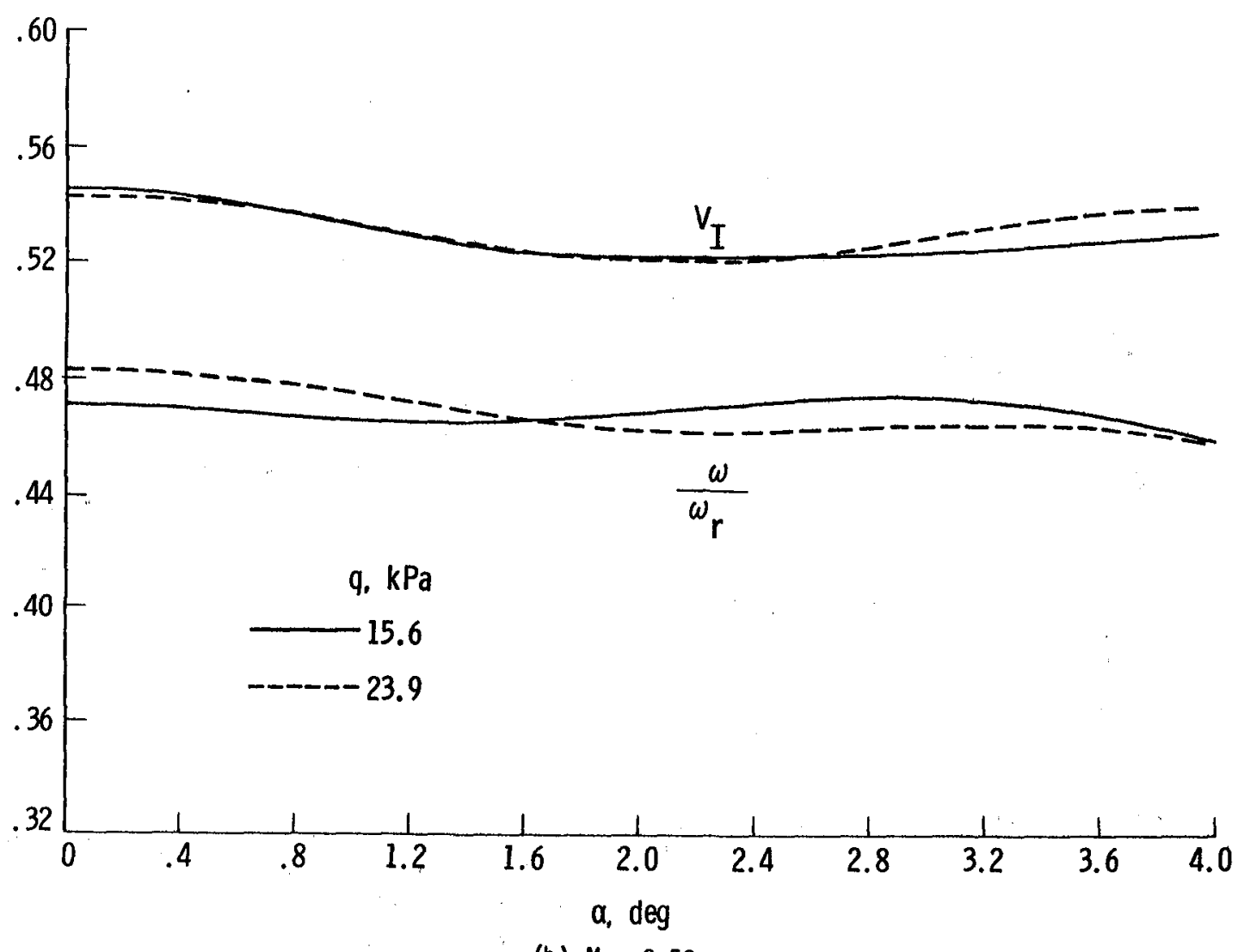

(b) $M=0.50$

Fig. 7 Continued. 


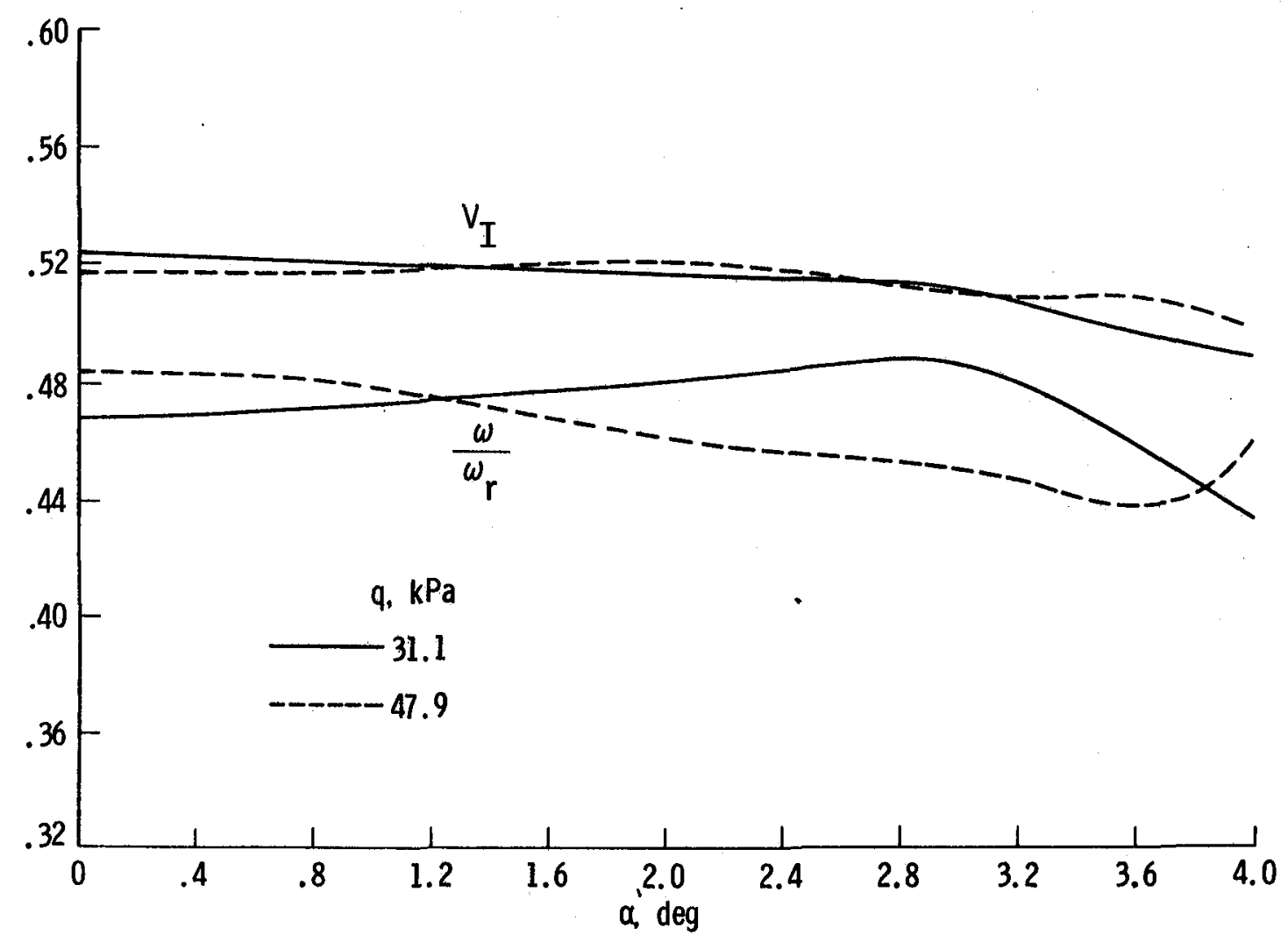

(c) $M=0.80$

Fig. 7 Continued

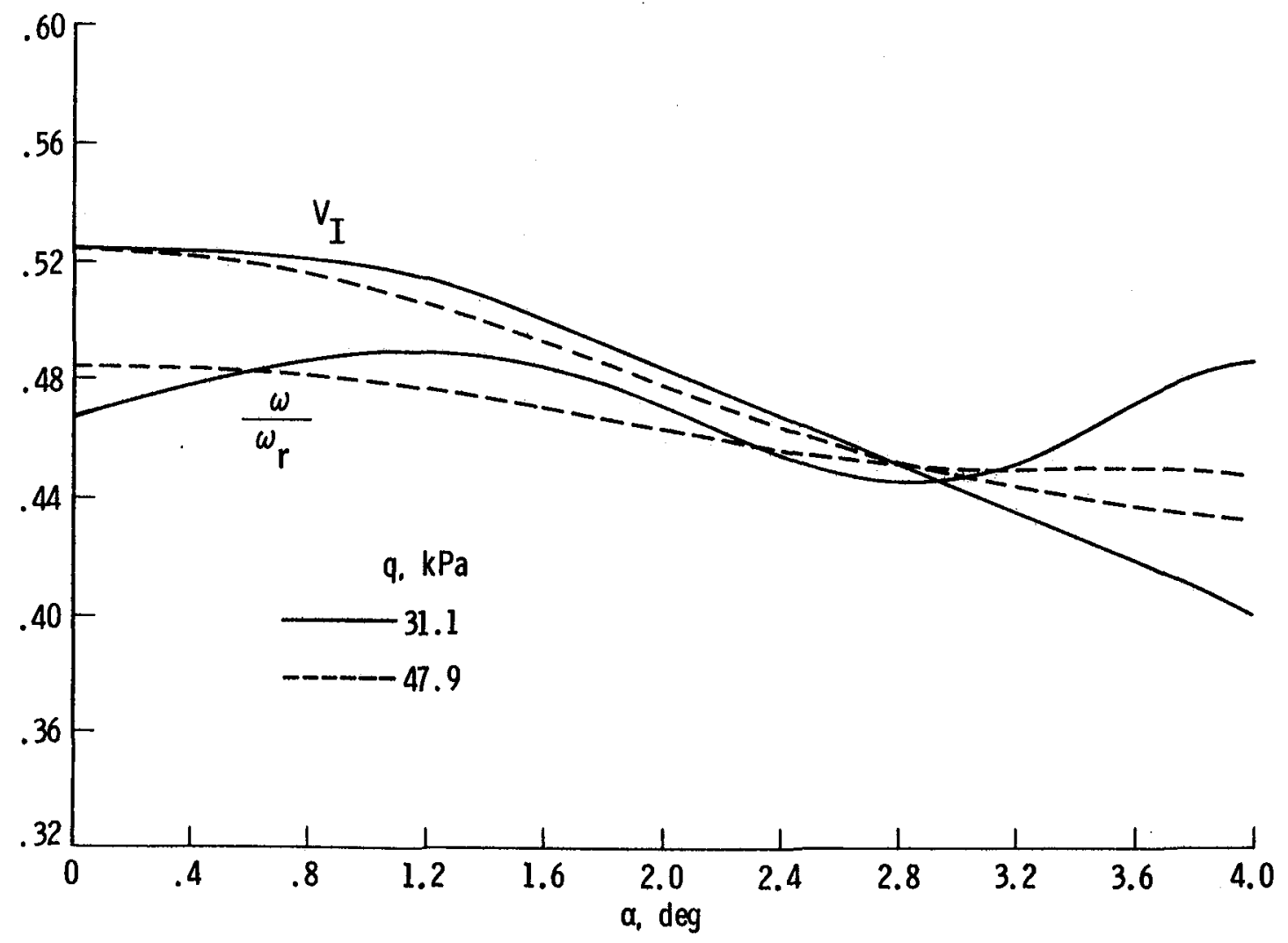

(d) $M=0.90$

Fig. 7 Continued. 


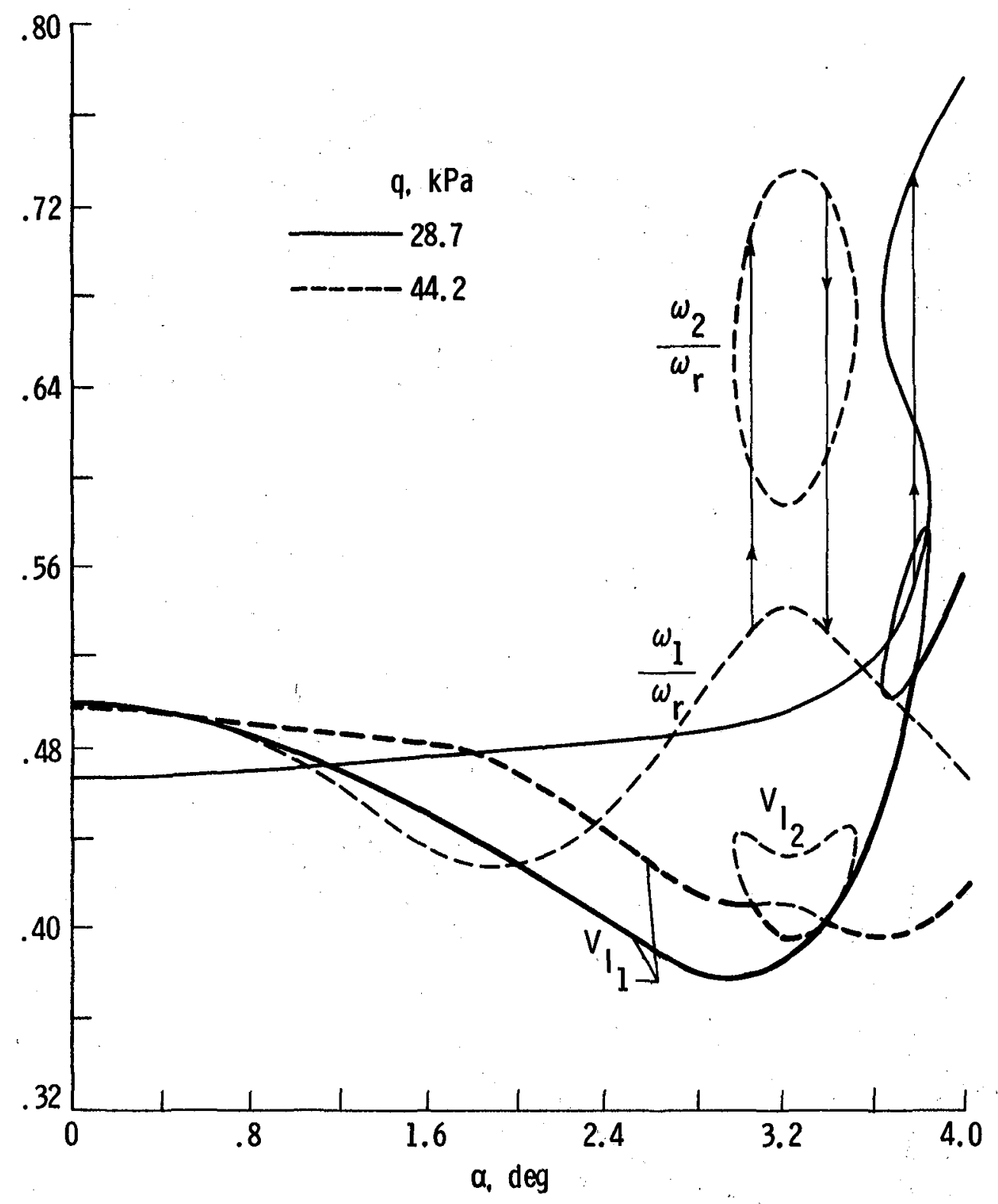

(e) $M=0.95$

Fig. 7 Continued. 


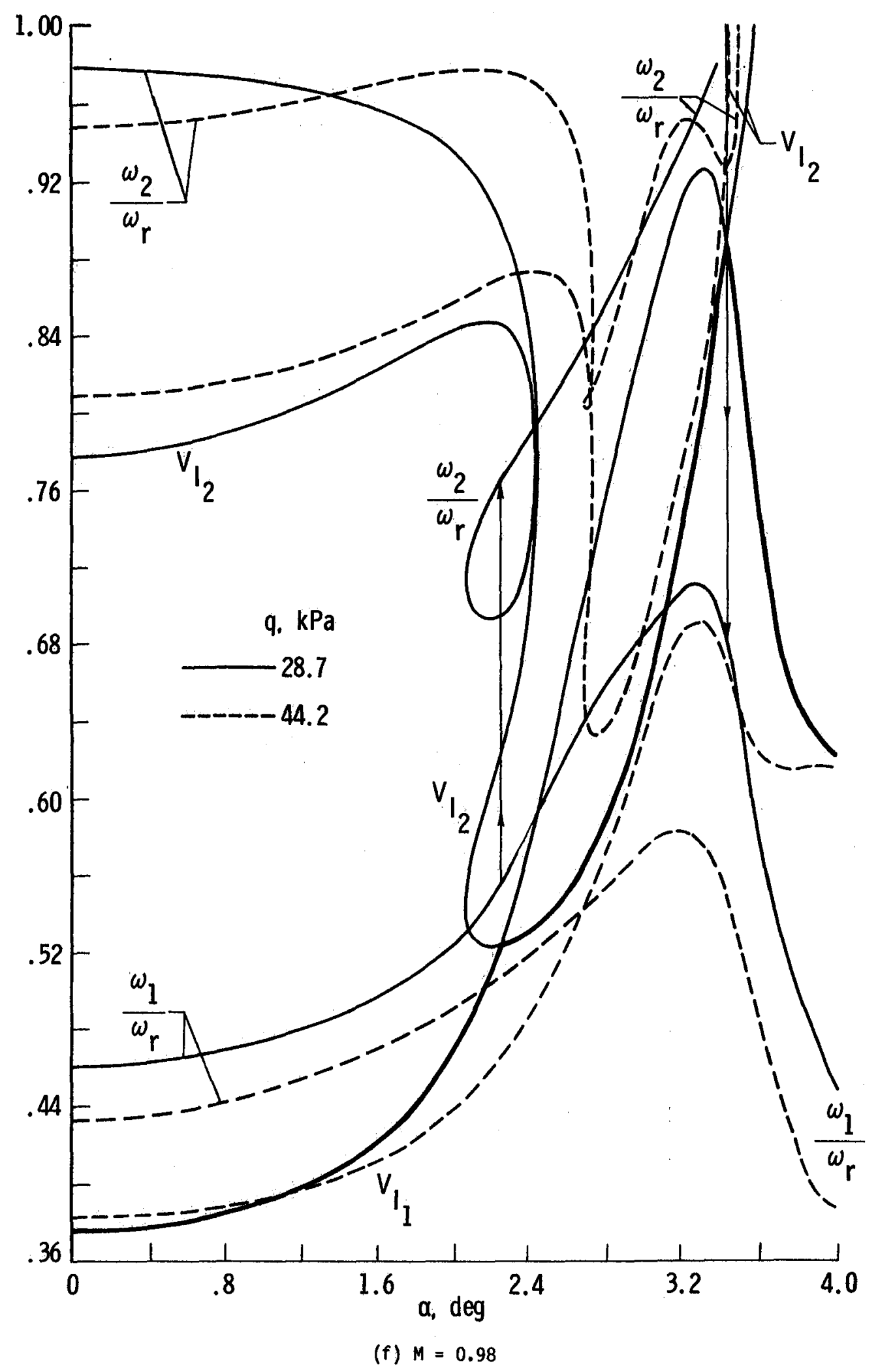

Fig. 7 Continued. 


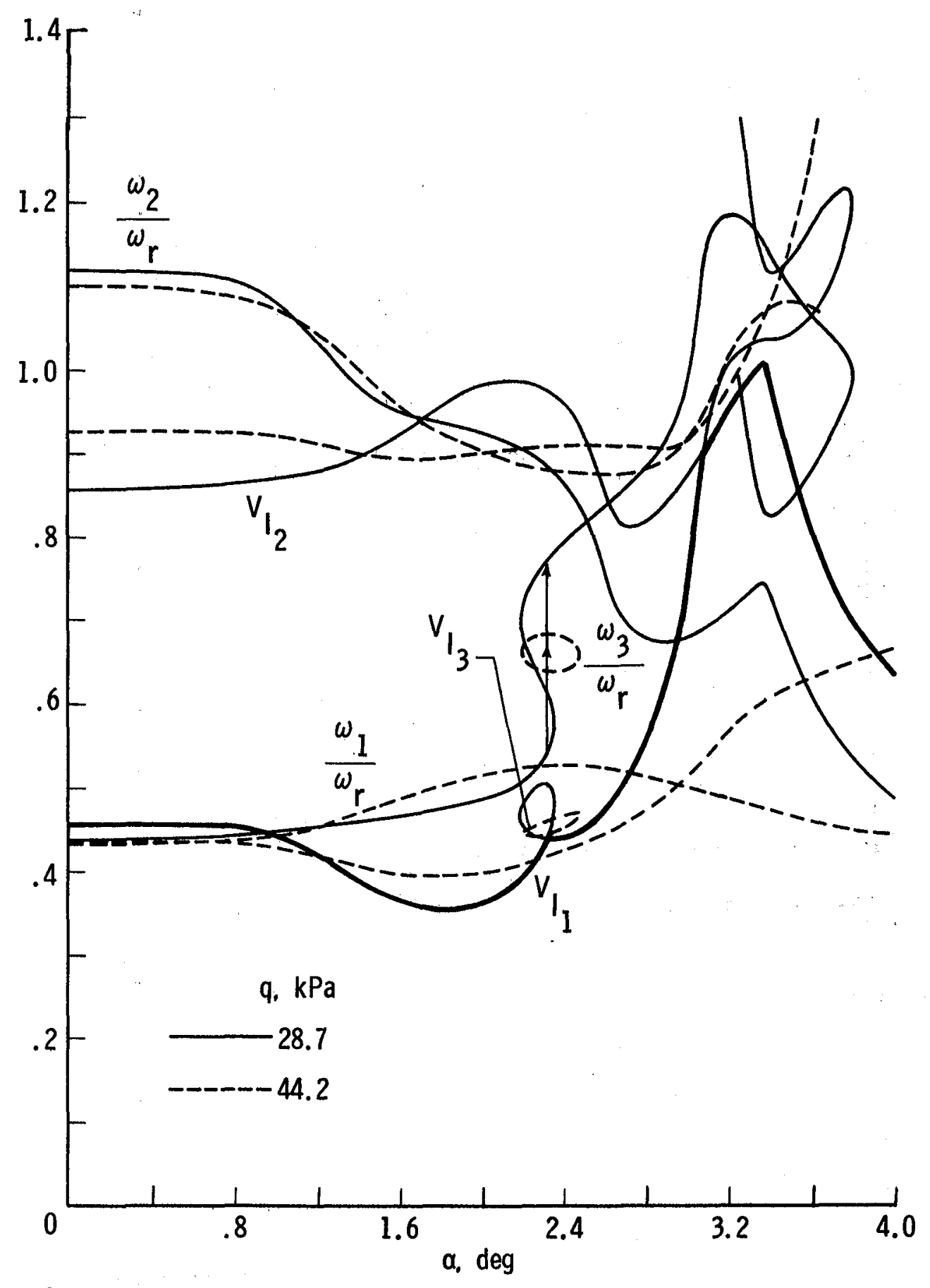

(g) $M=0.99$

Fig. 7 Continued. 


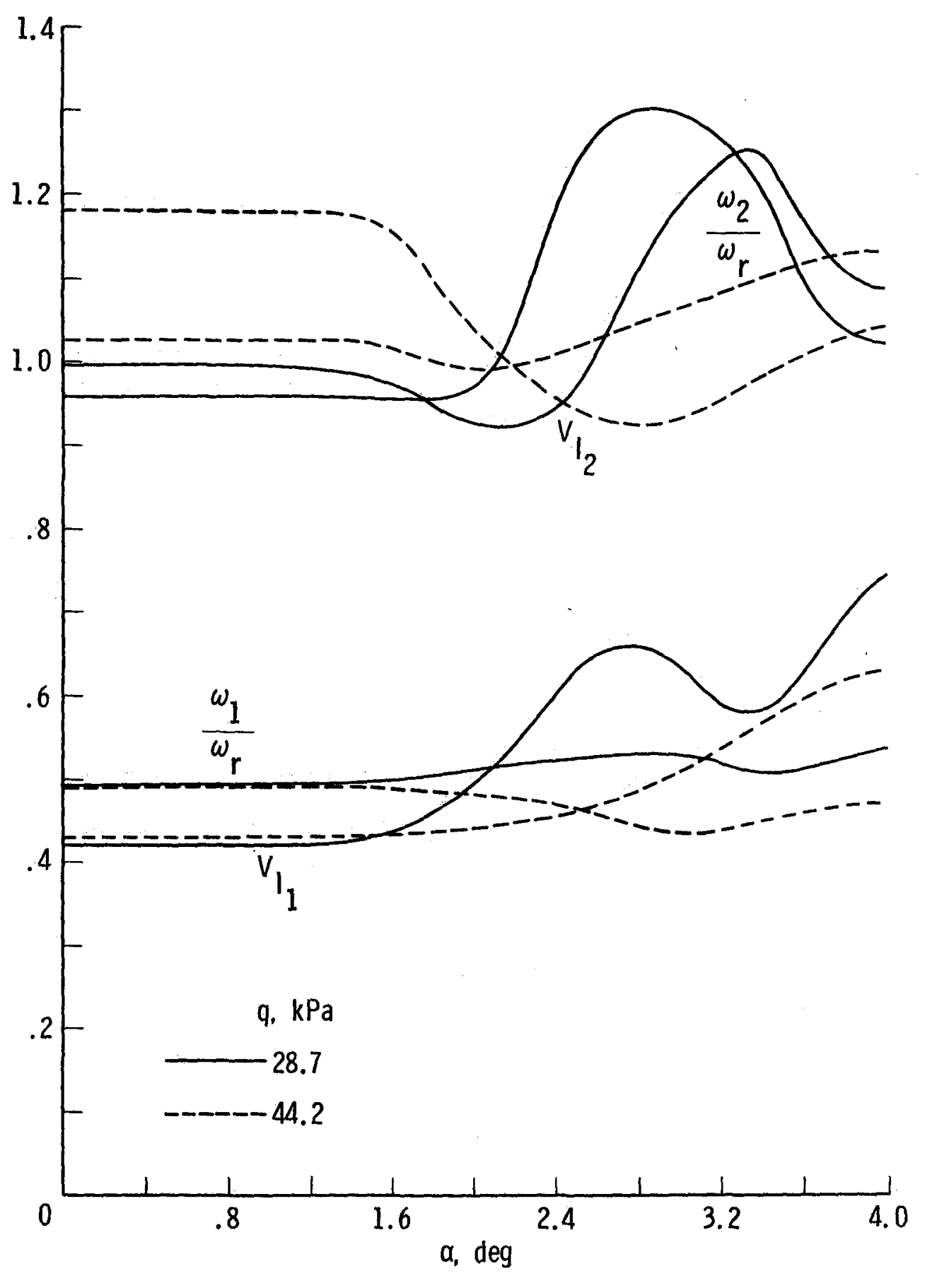

(h) $M=1.00$

Fig. 7 Concluded. 


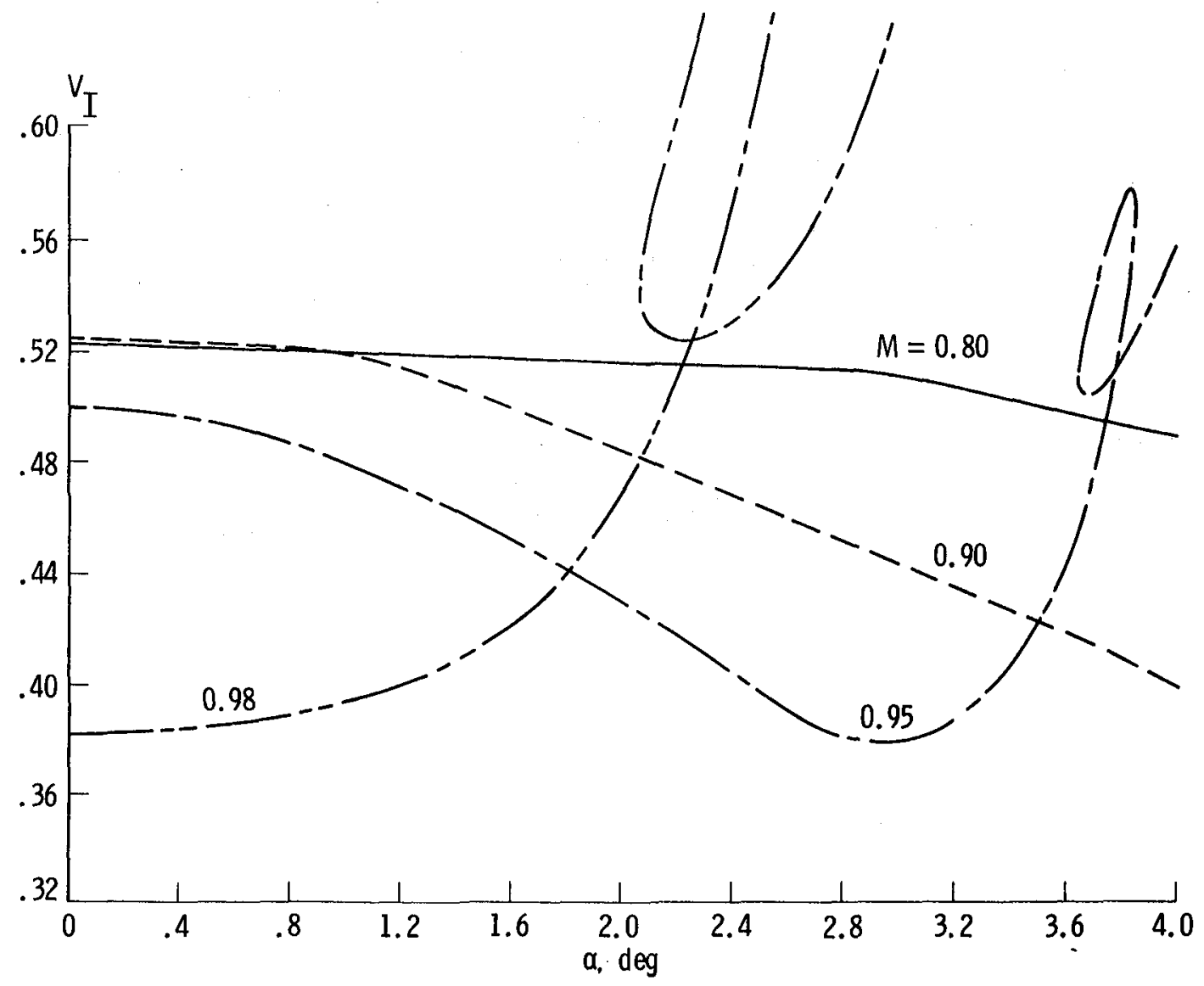

Fig. 8 Effect of Angle of Attack on Flutter at Constant Mach Number. $\mu_{r}=27.41$
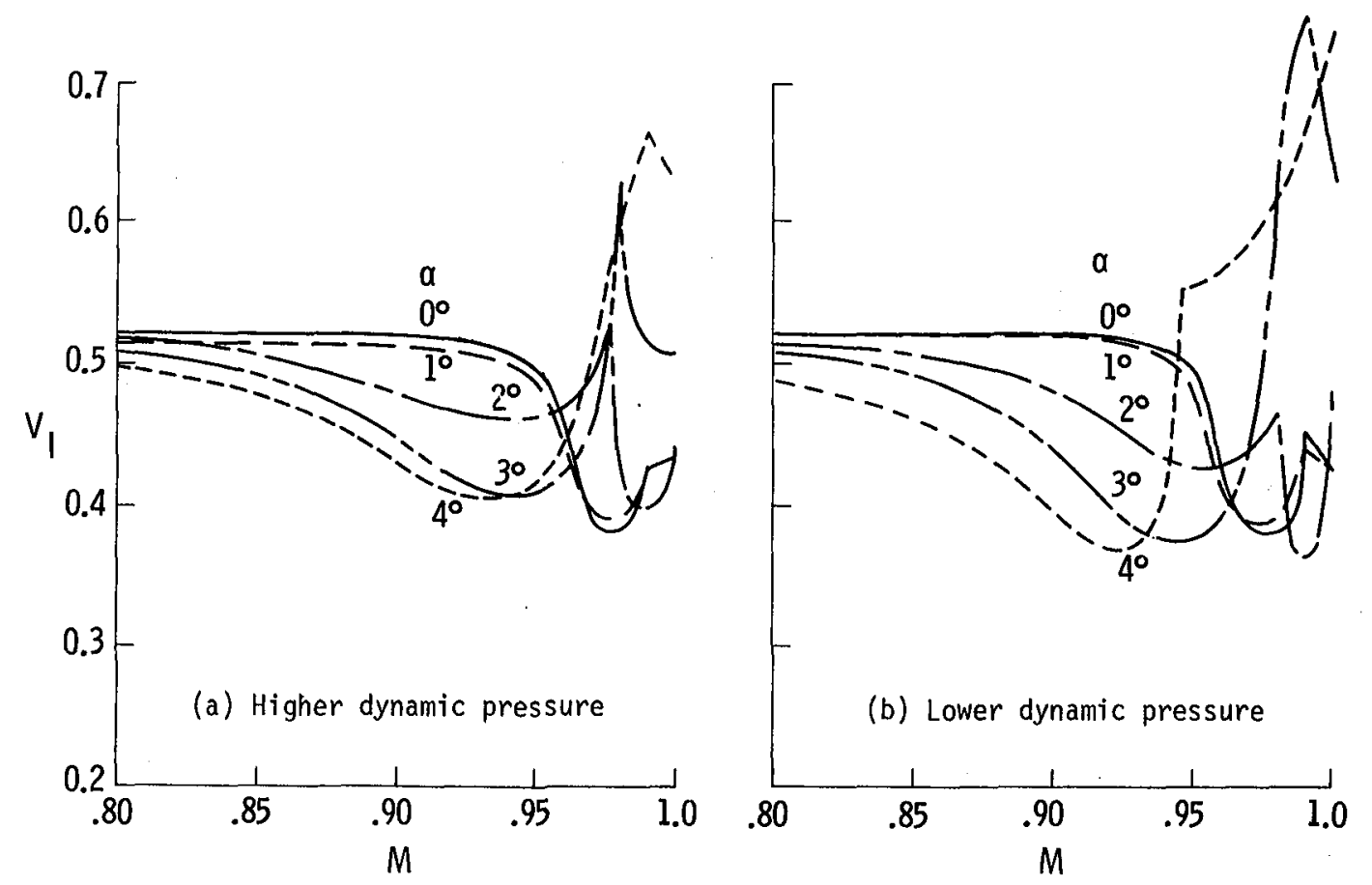

Fig. 9 Effect of Mach Number on Flutter at Constant Angle of Attack. $\mu_{r}=27.41$ 


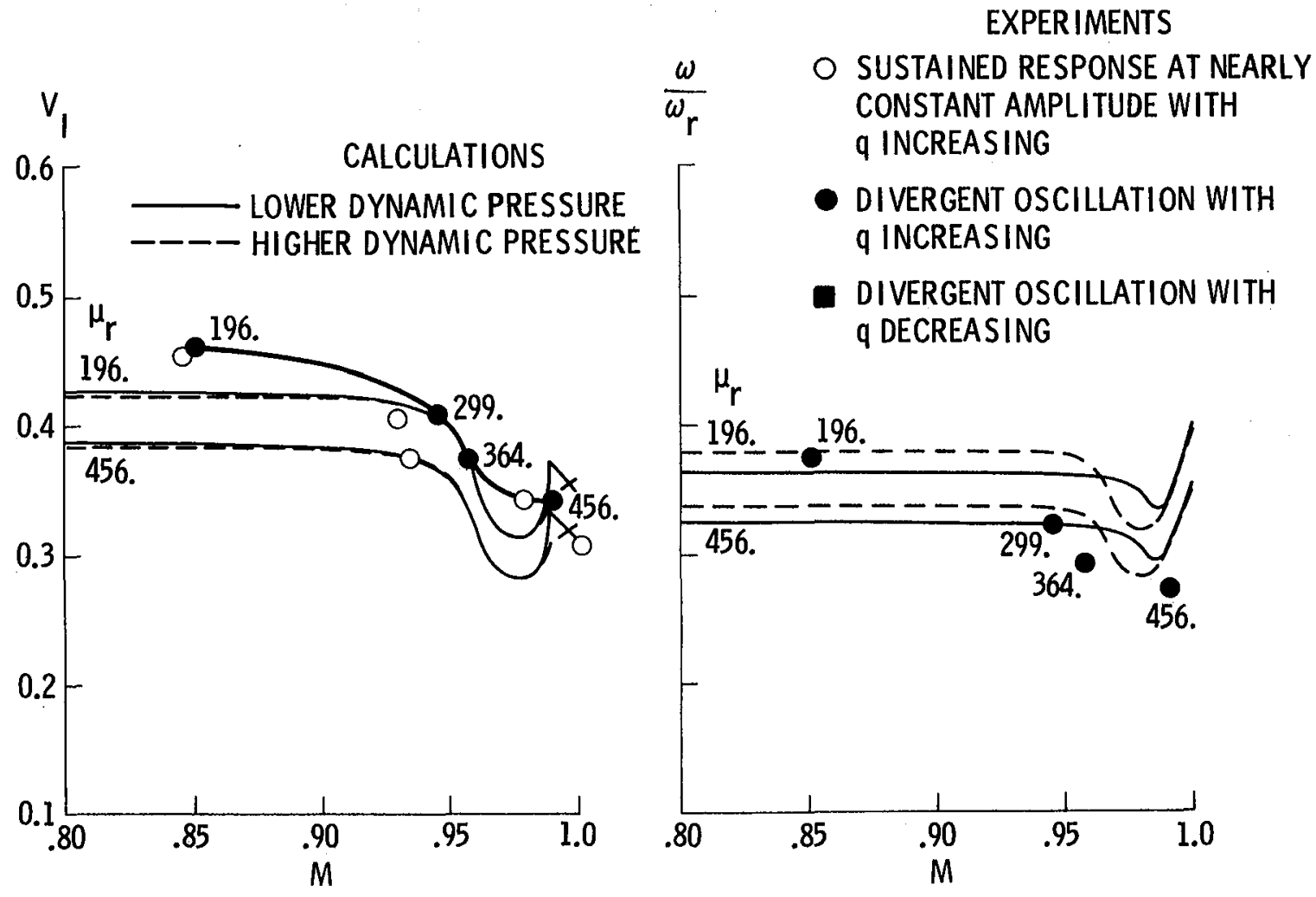

(a) $\alpha=0$

Fig. 10 Comparison of Calculated and Measured Flutter Characteristics
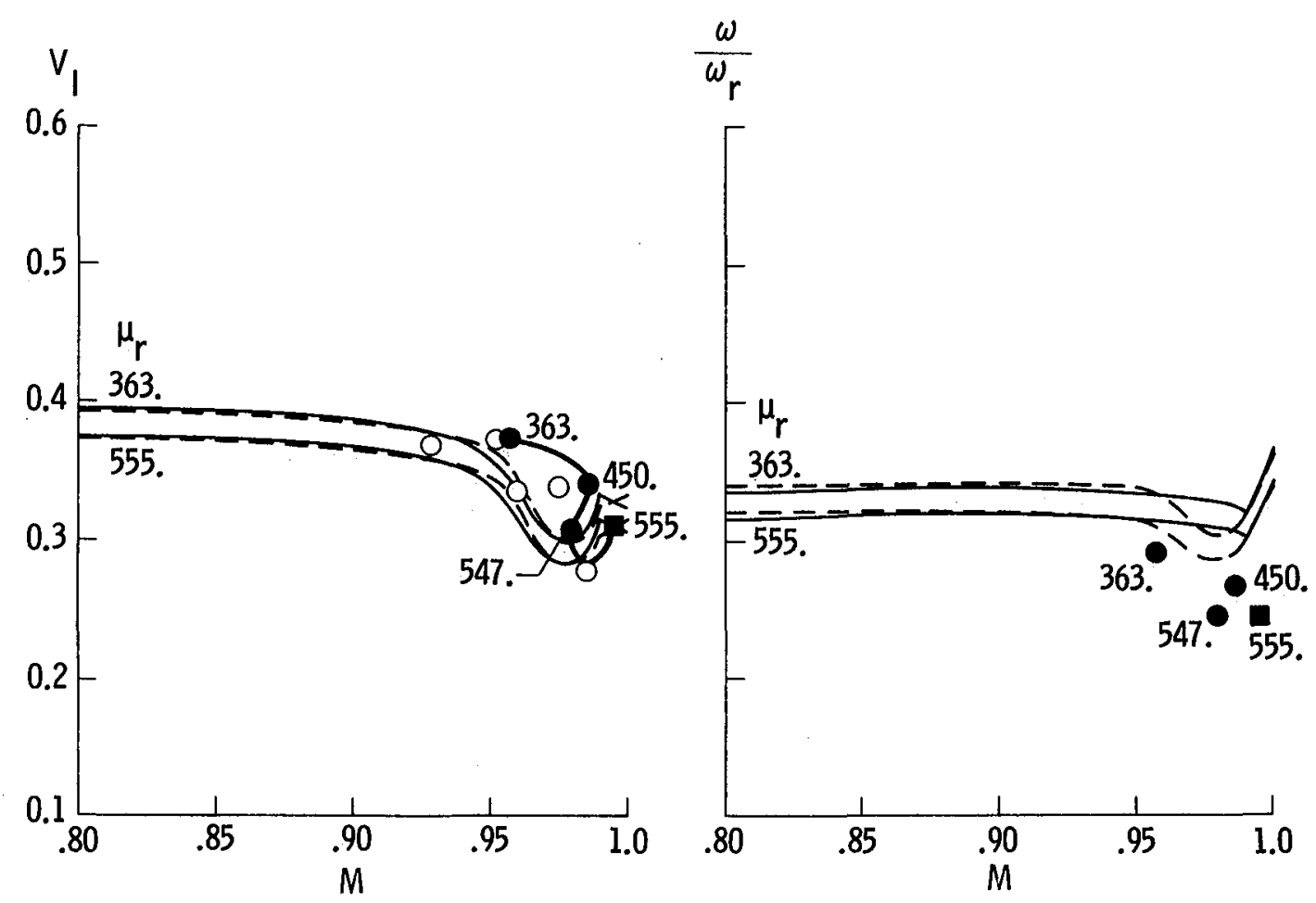

(b) $\alpha=10$

Fig. 10 Continued 

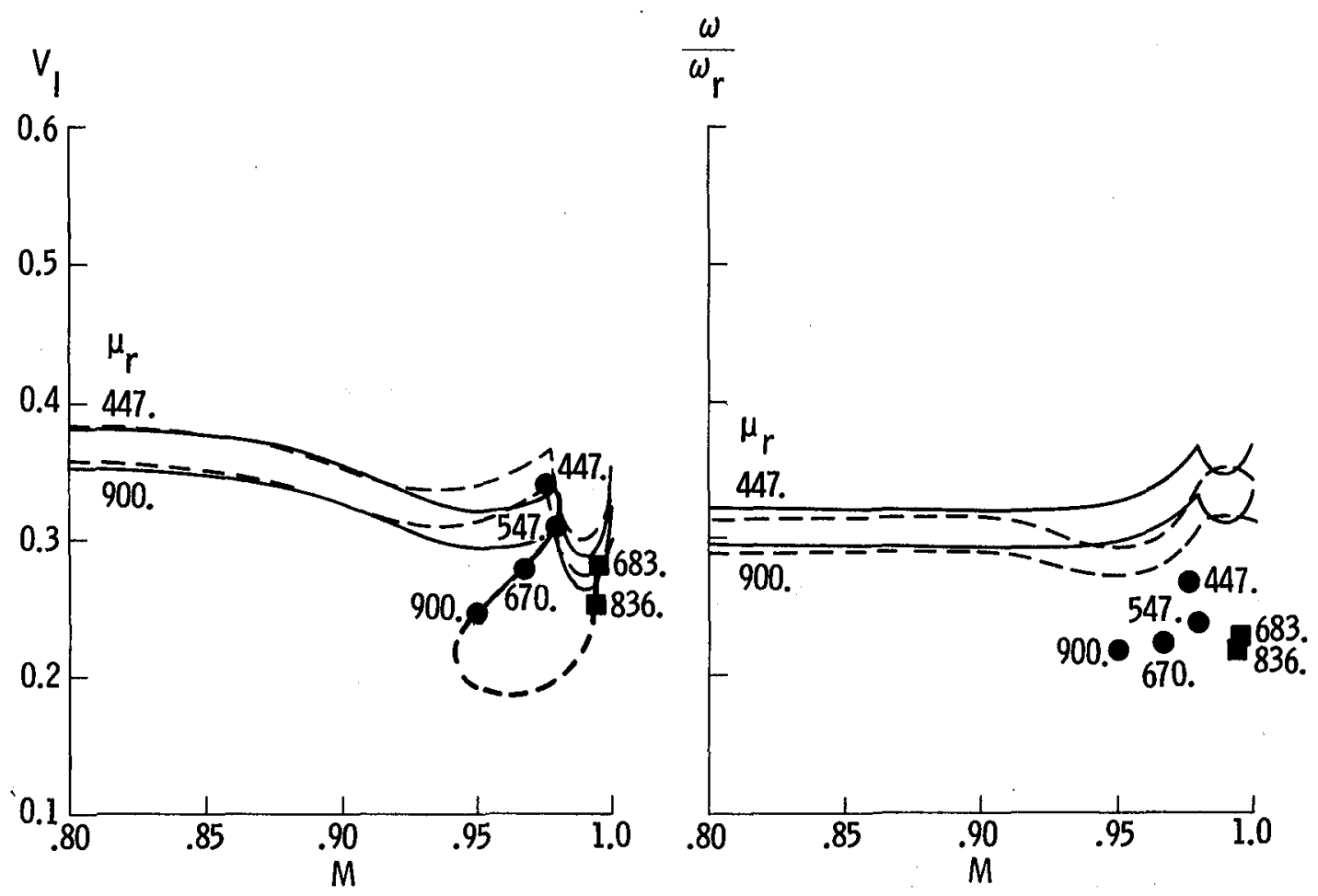

(c) $\alpha=2^{\circ}$

Fig. 10 Continued.

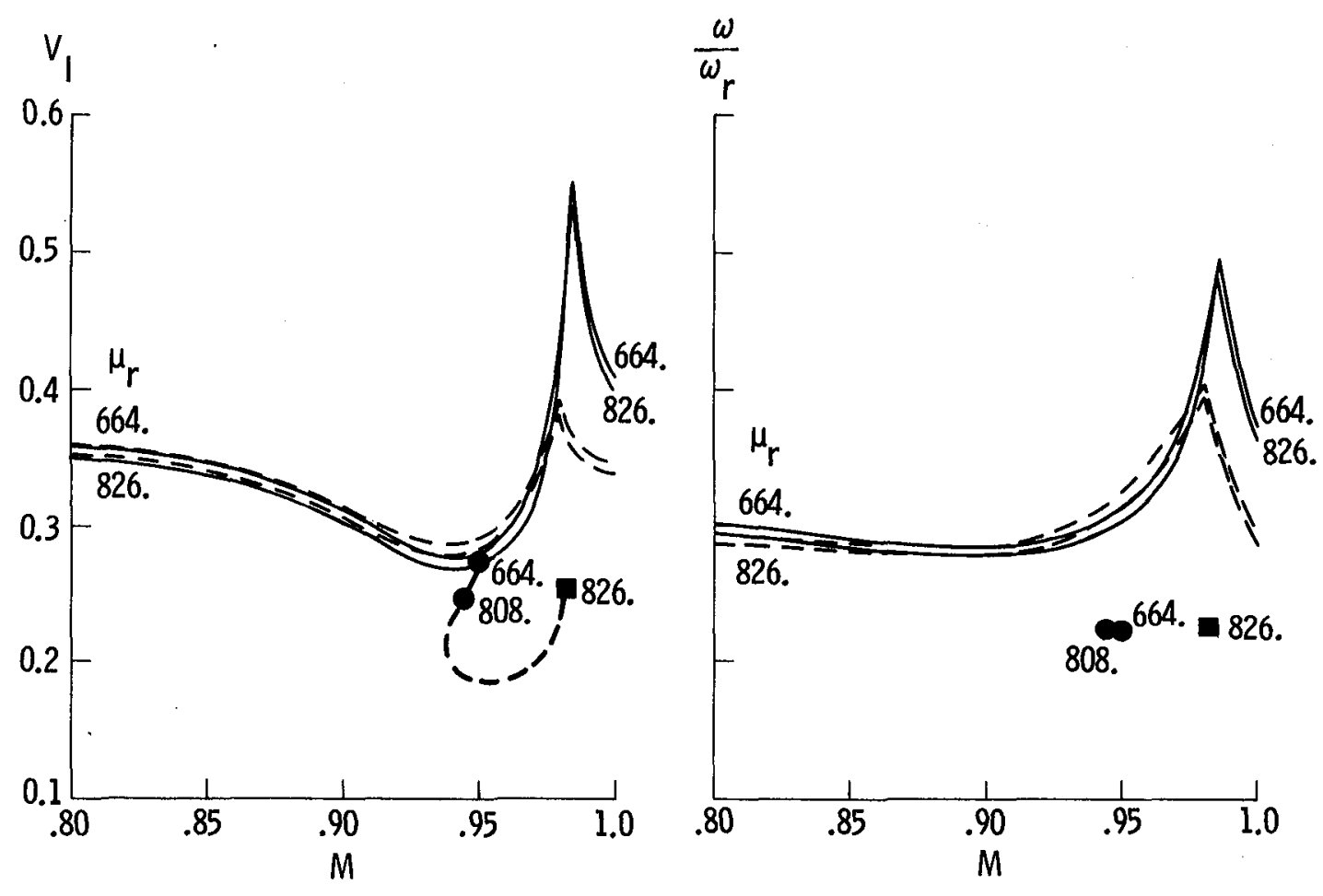

(d) $\alpha=3^{0}$

Fig. 10 Concluded 


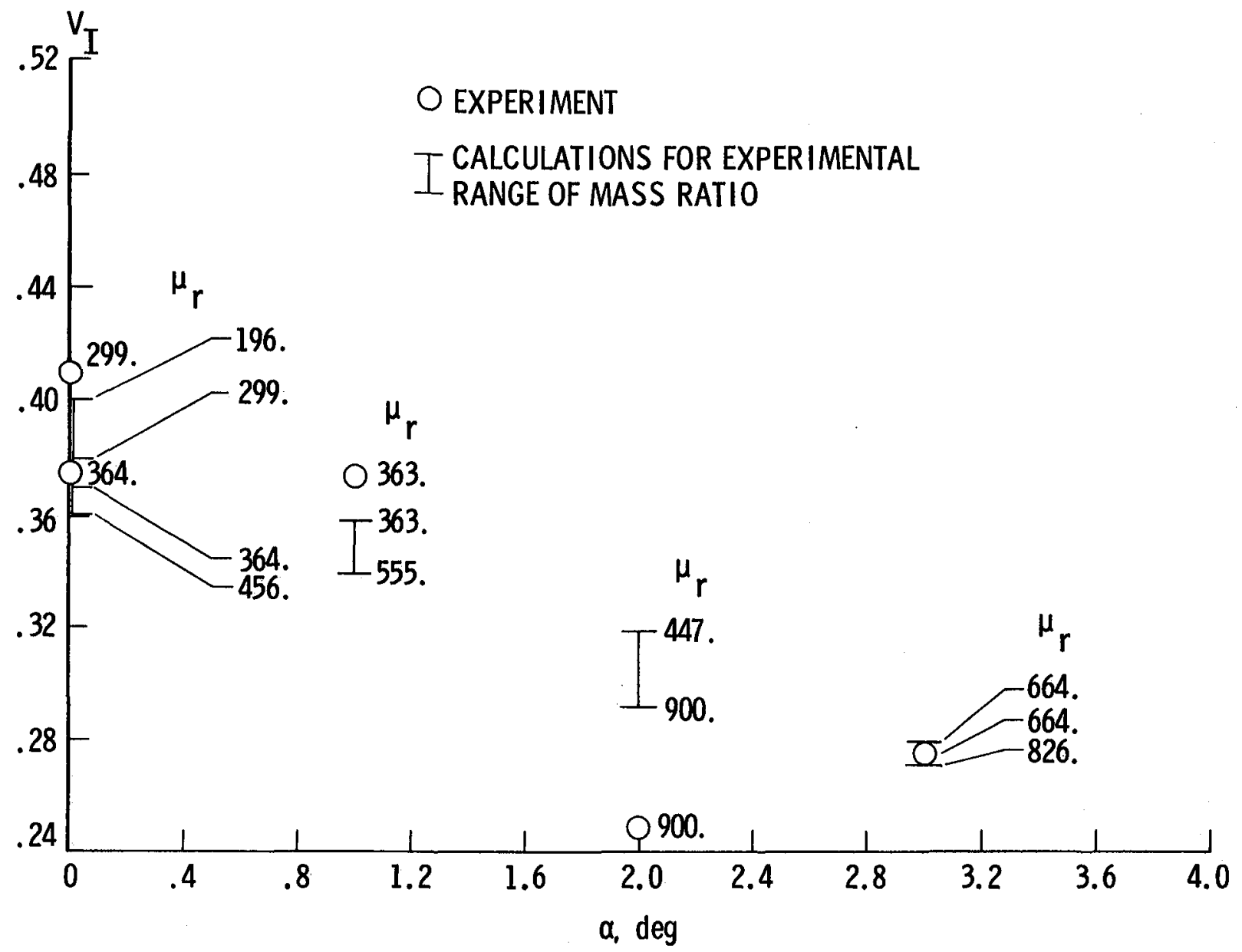

Fig. 11 Measured and Calculated Flutter Speeds for Mach Numbers near 0.95. (0.946<M<0.958) 



\begin{tabular}{|c|c|}
\hline $\begin{array}{l}\text { 1. Report No. } \\
\text { NASA TM } 83276\end{array}$ & 3. Recipient's Catalog No. \\
\hline \multirow{2}{*}{$\begin{array}{l}\text { 4. Title and Subtitle } \\
\text { MEASURED AND CALCULATED EFFECTS OF ANGLE OF ATTACK } \\
\text { ON THE TRANSONIC FLUTTER OF A SUPERCRITICAL WING }\end{array}$} & $\begin{array}{l}\text { 5. Report Date } \\
\text { August } 1982\end{array}$ \\
\hline & $\begin{array}{l}\text { 6. Performing Organization Code } \\
505-33-53-07\end{array}$ \\
\hline \multirow{2}{*}{$\begin{array}{l}\text { 7. Author(s) } \\
\text { E. Carson Yates, Jr., Eleanor C. Wynne, and } \\
\text { Moses G. Farmer }\end{array}$} & 8. Performing Organization Regort No. \\
\hline & \multirow{2}{*}{ 10. Work Unit No. } \\
\hline \multirow{3}{*}{$\begin{array}{l}\text { 9. Performing Organization Name and Address } \\
\text { NASA Langley Research Center } \\
\text { Hampton, VA } 23665\end{array}$} & \\
\hline & 11. Contract or Grme No. \\
\hline & 13. Type of beport and Perod Guvernes \\
\hline \multirow{2}{*}{$\begin{array}{l}\text { 12. Sponsoring Agency Name and Address } \\
\text { National Aeronautics and Space Administration } \\
\text { Washington, DC } 20546\end{array}$} & Technical Memorandum \\
\hline & 14. Sponsoring Aytumy Cote \\
\hline
\end{tabular}

16. Abstract

Flutter calculations have been made by modified strip analys is employing steady-state aerodynamic parameters obtained from published wind-tunnel pressure distributions. The results indicate that increasing angle of attack from zero can produce substantial changes in the transonic flutter characteristics that are favorable or unfavorable depending on Mach number and angle of attack. The results correlate well, in a qualitative sense, with the known aerodynamic behavior. The bottom of the transonic flutter-boundary "bucket" is shown to occur at lower Mach number as angle of attack increases.

The calculated flutter characteristics are in good agreement with the experimental data at zero angle of attack. At nonzero angles of attack, however, the experiments show sharply declining and backward-turning transonic flutter boundaries that are not indicated by the calculations. Published information indicates that such unconventional flutter boundaries may be caused by viscous effects at low Reynolds number which were not represented in the calculations. The present investigation indicates, however, that the occurrence of these unconventional transonic boundaries appears to be caused, at least to some extent, by variations in static aeroelastic deformation. A mechanism for the phenomenon is postulated.

17. Key Words (Suggested by Author(s))

Aeroelasticity

Flutter Analysis

Supercritical Wings

Transonic Flutter

Modified Strip Analysis
18. Distribution Statement

Unclassified - Unlimited

Subject Category 39

\begin{tabular}{|l|l|c|c|}
\hline $\begin{array}{l}\text { 19. Security Classif. (of this report) } \\
\text { Unclassified }\end{array}$ & $\begin{array}{l}\text { 20. Security Classif. (of this page) } \\
\text { Unclassified }\end{array}$ & $\begin{array}{c}21 . \text { No. of Pages } \\
29\end{array}$ & $A 03$ \\
\hline
\end{tabular}



